\title{
Ni Promotion by Fe: What Benefits for Catalytic Hydrogenation?
}

\author{
Dichao Shi, Robert Wojcieszak $®$, Sébastien Paul@ and Eric Marceau * \\ Université de Lille, CNRS, Centrale Lille, ENSCL, Université d'Artois, UMR 8181-UCCS—Unité de Catalyse et \\ Chimie du Solide, F-59000 Lille, France; dichao.shi@phd.centralelille.fr (D.S.); \\ robert.wojcieszak@univ-lille.fr (R.W.); sebastien.paul@centralelille.fr (S.P.) \\ * Correspondence: eric.marceau@univ-lille.fr; Tel.: +33-3-20-43-69-44
}

Received: 26 April 2019; Accepted: 11 May 2019; Published: 15 May 2019

\begin{abstract}
Metallic nickel is known to efficiently catalyze hydrogenation reactions, but one of its major drawbacks lies in its lack of selectivity, linked to side-reactions of hydrogenolysis and over-hydrogenation. More selective hydrogenations can be obtained upon the introduction of a second metal in combination with $\mathrm{Ni}$. Fe is an interesting choice, as it is a cheap and abundant metal. This review aims at discussing the advantages and constraints brought by the preparation procedures of bimetallic supported Ni-Fe nanoparticles, and at analyzing the benefits one can draw by substituting Ni-Fe supported catalysts for Ni monometallic systems for the catalytic hydrogenation of organic molecules. Specific formulations, such as $\mathrm{Ni}_{75} \mathrm{Fe}_{25}$, will be singled out for their high activity or selectivity, and the various hypotheses behind the roles played by Fe will be summarized.
\end{abstract}

Keywords: Nickel; iron; bimetallic catalysts; hydrogenation; hydrogenolysis

\section{Introduction}

Compared to noble metals, non-noble metals such as $\mathrm{Fe}, \mathrm{Co}, \mathrm{Ni}$ and $\mathrm{Cu}$ are attractive alternatives for catalytic hydrogenations because of their low cost. However, Fe is often the least active metal of the series and deactivates easily, $\mathrm{Co}$ is the most expensive one, and $\mathrm{Cu}$ usually exhibits a low activity due to the difficulty of having it highly dispersed on a support. Metallic nickel stands out as the best compromise. Raney nickel has been used for almost one century as a catalyst in organic chemistry, in the laboratory and industry [1]. However, one of its most important drawbacks is its pyrophoricity, because of which it must be handled under an inert atmosphere. Another disadvantage of nickel is its fast deactivation due to the deposition of carbon and formation of carbide. Finally, a major problem with Ni-based catalysts is their possible lack of selectivity in the hydrogenation of oxygen- or nitrogen-containing functions, as they are highly active both in the hydrogenation of carbon-carbon bonds and of aromatic rings, and in hydrogenolysis side-reactions.

The addition of a second metal as a promoter is known to effectively modify the properties of $\mathrm{Ni}$ catalysts [2]. Bimetallic Ni-based catalysts exhibit specific properties, via a synergistic or bi-functional effect, which differ from those of the parent metals and offer the opportunity to design catalysts with an activity and selectivity that exceed those achievable with monometallic nickel. Because the size and composition of bimetallic particles affect their catalytic properties, these parameters should be precisely characterized and optimized in order to correlate the catalyst formulation and its performances in reaction.

Iron has been cited as a promising promoter of nickel in bimetallic $\mathrm{Ni}-\mathrm{Fe}$ combinations because of its low cost, of its abundance and of its effective enhancement of catalytic performances (promoter is understood here in a general sense of boosting catalytic performances, which does not necessarily imply that Fe is added in minor proportions). Since the 1980s, supported Ni-Fe catalysts have been 
described as promising systems in three major domains: The catalytic reforming of methane or of organic molecules, for which Ni-Fe systems present a gain of stability compared with monometallic $\mathrm{Ni}$, linked to a slower rate of carbidization [3-8]; the hydrogenation of $\mathrm{CO}$ and $\mathrm{CO}_{2}$, to methane or $\mathrm{C}_{2+}$ hydrocarbons, for which an increase of activity and selectivity to $\mathrm{CH}_{4}$ or short olefins, depending on the reaction conditions, has been noted [9-16]; finally, the selective hydroconversion of organic molecules. Since the first results published in 1992 by Kumbhar et al. on the selective hydrogenation of ketones and nitriles [17], about 20 papers have appeared so far on the hydroconversion of organic molecules on Ni-Fe supported catalysts, 18 since 2013 and 10 since 2017, which emphasizes the potential of these systems for this family of applications. However, a survey of the literature also shows that standard preparation methods for Ni-Fe bimetallic catalysts, such as co-impregnation, may yield metal particles of different size or composition $[5,10,17,18]$. As a consequence, owing to a lack of control of the nature of the individual nanoparticles (alloyed vs. segregated metals, disparities in metal content), the existence of a general correlation between the nanoparticles composition and the best catalytic results in the hydrogenation of organic molecules, as for now, remains an open question. The present review aims at discussing the advantages and constraints brought by different preparation procedures of bimetallic supported Ni-Fe nanoparticles, and at analyzing the benefits the literature has reported upon substituting Ni-Fe supported catalysts for $\mathrm{Ni}$ systems for the selective hydrogenation of organic molecules. We will summarize the various hypotheses explaining the action of Fe with respect to these catalytic reactions, identify the most promising formulations, and suggest which lines of research appear as key issues for the future.

In order to make comparisons easier between the different articles, the formulation of the catalysts described in the literature will be written in the following way: (Total metal content, $\mathrm{wt} \%$ ) $\mathrm{Ni}_{x} \mathrm{Fe}_{(100-x)} /$ support, where $\mathrm{x}$ and (100-x) represent the respective molar proportions of the two metals in the catalyst formulation.

\section{Structure, Size, Composition and Formation of Ni-Fe Supported Nanoparticles}

The nominal proportions of $\mathrm{Ni}$ and $\mathrm{Fe}$, the preparation method of $\mathrm{Ni}-\mathrm{Fe}$ catalysts, the temperature of reduction, the nature of the support, all have an influence on the structure of supported $\mathrm{Ni}-\mathrm{Fe}$ nanoparticles, on their size and on their actual metals content, which are likely to affect the performances of the catalyst in the hydrogenation of organic molecules. This section provides elements for a better understanding of the relationships existing between these experimental parameters and the structural characteristics of $\mathrm{Ni}-\mathrm{Fe}$ nanoparticles.

\subsection{Influence of the Metals Content on the Structure of $\mathrm{Ni}-\mathrm{Fe}$ Nanoparticles}

According to the simplified phase diagram published in 1937 by Bradley et al. (Figure 1a) [19], the Ni-Fe bulk alloy displays two different crystal structures, depending on the Fe and Ni contents, and on the temperature. The $\alpha$ phase, containing less than 8 at $\%$ of $\mathrm{Ni}$, exhibits a body-centered cubic structure (bcc), like metallic Fe, while the $\gamma$ phase, containing more than 32 at $\%$ of Ni, exhibits a face-centered cubic structure (fcc), like monometallic Ni. Solubility between Fe and Ni does not extend to the whole composition range, and compositions between 8 and 32 at $\%$ lead to a mixture of bcc and fcc phases after cooling. Except for the lowest Ni contents, for which the alloy retains the bcc structure, the fcc phase dominates above $400{ }^{\circ} \mathrm{C}$. More complex phase diagrams based on the study of meteorites include the existence of intermediate phases in the $\gamma$ domain, such as awaruite, of average composition $\mathrm{FeNi}_{3}$, as shown in Figure $1 \mathrm{~b}$ [10].

In the literature dedicated to $\mathrm{Ni}-\mathrm{Fe}$ catalysts, experimental results generally follow the trend given by the simpler diagram. Matsuyama et al. reported that Fe-rich alloys $(<5 \mathrm{at} \% \mathrm{Ni})$ exhibit the bcc structure, while Ni-rich alloys ( $>40$ at $\% \mathrm{Ni}$ ) exhibit the fcc structure, the intermediate range corresponding to a mixture between particles of the two varieties [20]. This co-existence on supported catalysts has indeed been noted for nominal formulations $\mathrm{Ni}_{20} \mathrm{Fe}_{80}, \mathrm{Ni}_{25} \mathrm{Fe}_{75}$ and $\mathrm{Ni}_{33} \mathrm{Fe}_{67}$ [14,17,21-24]. De-mixing has sometimes been mentioned to occur for preparations based on nominal formulations 
expected to fall in the $\gamma$ domain, such as $\mathrm{Ni}_{50} \mathrm{Fe}_{50}$ or $\mathrm{Ni}_{71} \mathrm{Fe}_{29}[21,24,25]$. The identification of the ordered intermediate $\mathrm{Ni}_{75} \mathrm{Fe}_{25}$ phase has been mentioned in a few instances [26,27].

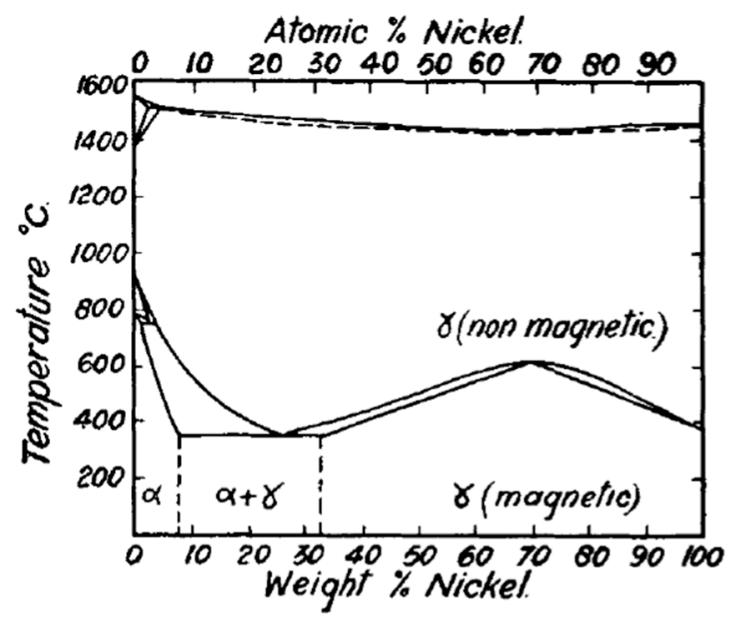

(a)

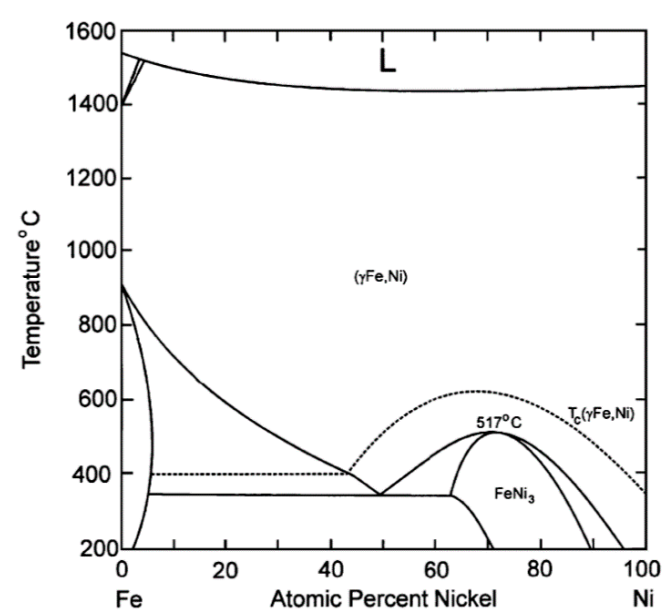

(b)

Figure 1. (a) Simplified phase diagram of the bulk Fe-Ni system. Reprinted from Reference [19] with permission from Taylor and Francis Ltd, www.informaworld.com; (b) phase diagram evidencing the existence of an intermediate phase, awaruite, of average composition $\mathrm{FeNi}_{3}$. Reprinted from Reference [10], copyright 2007, with permission from Elsevier.

Fe is a slightly larger atom than $\mathrm{Ni}$ (empirical atomic radius: $0.126 \mathrm{vs} .0 .124 \mathrm{~nm}$ ). As a consequence, the lattice parameter of the fcc cell in the $\gamma$ domain decreases when the Ni content increases. This trend globally follows a linear Vegard's law, as has been verified by several teams $[4,8,28]$. The evidence for alloying, and the composition of $\mathrm{Ni}-\mathrm{Fe}$ particles, can thus be derived from X-ray diffraction (XRD) measurements.

\subsection{Synthesis Routes for Supported Ni-Fe Nanoparticles: Influence on the Particles Size and Composition}

Three easy-to-scale methods have been principally used for the preparation of supported $\mathrm{Ni}-\mathrm{Fe}$ bimetallic catalysts: Co-impregnation, and, to a lesser extent, sol-gel routes and precipitation, with different outcomes in terms of particle size and composition. We will list below the characteristics of these three methods, their advantages and their limits.

\subsubsection{Incipient Wetness Impregnation}

Incipient wetness impregnation (IWI) is a classical way to prepare Ni-Fe supported catalysts. The porous support is wetted by an aqueous solution containing the Fe and Ni precursors (usually $\mathrm{Fe}(\mathrm{III})$ and $\mathrm{Ni}(\mathrm{II})$ nitrates) in the proper $\mathrm{Fe} / \mathrm{Ni}$ ratio. The volume of the solution is equal to the pore volume of the support. Drying, calcination in oxidative atmosphere and reduction steps are subsequently performed to obtain reduced $\mathrm{Ni}-\mathrm{Fe}$ particles.

The phases detected by XRD and ${ }^{57} \mathrm{Fe}$ Mössbauer spectroscopy after calcination are usually the two monometallic metal oxides, $\mathrm{Fe}_{2} \mathrm{O}_{3}$ and $\mathrm{NiO}$. Ni-Fe mixed oxides have also been identified. Despite the detection of $\alpha-\mathrm{Fe}_{2} \mathrm{O}_{3}$ by XRD in $\mathrm{Ni}-\mathrm{Fe} / \mathrm{SiO}_{2}$ and $\mathrm{Fe} / \mathrm{SiO}_{2}$ catalysts, a difference in the half linewidths of the Mössbauer peaks, significantly broadened for $\mathrm{Ni}-\mathrm{Fe} / \mathrm{SiO}_{2}$ compared with $\mathrm{Fe} / \mathrm{SiO}_{2}$, suggested that iron ions had nickel second-shell neighbors. The oxide was thus designated as $\alpha-\mathrm{Fe}_{2-\zeta} \mathrm{Ni}_{\zeta} \mathrm{O}_{3}$, for $\mathrm{Ni}$-doped $\mathrm{Fe}_{2} \mathrm{O}_{3}$. A low intensity of $\mathrm{NiO}$ XRD reflections also suggested that most of $\mathrm{Ni}$ was in fact present in substitution in iron oxides [23]. In the second case, the $\mathrm{NiFe}_{2} \mathrm{O}_{4}$ phase was identified by XRD [29]. IWI thus does not ensure a complete association of the two metals during the first stages of the catalyst preparation. However, doping of iron oxides by $\mathrm{Ni}^{2+}$ ions (or, conversely, of cubic $\mathrm{NiO}$ by iron ions) probably occurs, but can be hardly evidenced by routine characterization techniques 
such as XRD. Because they do now allow an early association between the two metals, successive impregnations may be less successful than co-impregnation [24,30,31].
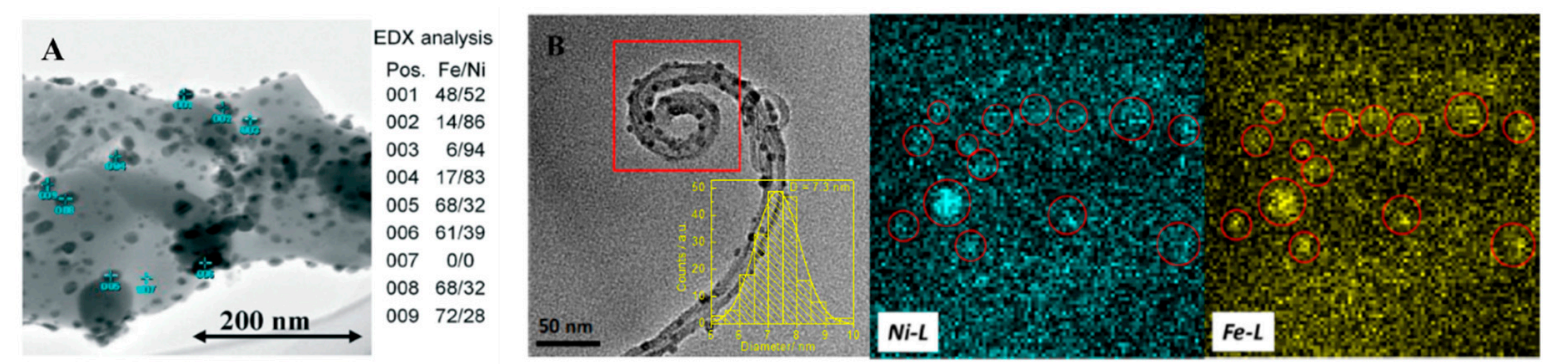

Figure 2. (A) TEM image and EDX analysis of an $18 \mathrm{wt} \% \mathrm{Ni}_{67} \mathrm{Fe}_{33} / \alpha-\mathrm{Al}_{2} \mathrm{O}_{3}$ catalyst prepared by co-impregnation and reduced at $500{ }^{\circ} \mathrm{C}$. Republished with permission of the Royal Society of Chemistry, from Reference [5]; permission conveyed through Copyright Clearance Center, Inc.; (B) High-resolution transmission electron microscopy (HRTEM) image, size histogram and STEM-EDX mapping of a $6.6 \mathrm{wt} \% \mathrm{Ni}_{83} \mathrm{Fe}_{17} /$ carbon nanotubes catalyst prepared by co-impregnation and reduced at $400{ }^{\circ} \mathrm{C}$. Reprinted from Reference [32], copyright 2017, with permission from Elsevier.

The reduction temperature of the oxidic phases usually ranges between 300 and $500{ }^{\circ} \mathrm{C}$. A usual drawback from IWI, as has been recently reviewed by Tomishige et al. [5], is that the particle size distribution of reduced Ni-Fe nanoparticles may be broad or bimodal, with a co-existence between particles smaller and larger than $10 \mathrm{~nm}$ (Figure 2A) [18,25,33]. Mild drying under vacuum prior to reduction has been reported to limit the growth of the particles [25], possibly because anhydrous nitrates do not melt and diffuse upon heating over the support surface.

An alternative way to form $\mathrm{Ni}-\mathrm{Fe}$ particles on a carbonaceous support, without reduction in $\mathrm{H}_{2}$, was proposed by Chieffi et al. [34]. Carbon-supported Ni-Fe nanoparticles were prepared by carbothermal reduction of a cellulose filter paper impregnated with $\mathrm{Fe}(\mathrm{III})$ and $\mathrm{Ni}$ (II) nitrates, at $800^{\circ} \mathrm{C}$ for $2 \mathrm{~h}$ under nitrogen. The shape and size of the cellulose fibers was retained after heat-treatment. The crystallite size of Ni-Fe nanoparticles was comprised of between 20 and $30 \mathrm{~nm}$.

Another problem with IWI is the possible disparities in the composition of Ni-Fe particles on a given catalyst, which can supposedly result from the non-uniform composition of the oxidic phases formed upon calcination. It is difficult to identify the precise origin of the problem, which can derive from the characteristics of support and/or of the conditions of drying. For example, Wang et al. prepared a series of $\mathrm{Ni}-\mathrm{Fe} / \alpha-\mathrm{Al}_{2} \mathrm{O}_{3}$ catalysts with different $\mathrm{Fe} / \mathrm{Ni}$ ratios [18]. For a $\mathrm{Ni}_{67} \mathrm{Fe}_{33}$ formulation $(\mathrm{Fe} / \mathrm{Ni}$ ratio $=0.5)$, the actual $\mathrm{Fe} / \mathrm{Ni}$ ratio measured by energy-dispersive $\mathrm{X}$-ray spectroscopy (EDX) widely varied in the range 0.06-2.6 (Figure 2a). Kumbhar et al. also found that $20 \mathrm{wt} \% \mathrm{Ni}_{75} \mathrm{Fe}_{25} / \mathrm{SiO}_{2}$ and $20 \mathrm{wt} \% \mathrm{Ni}_{50} \mathrm{Fe}_{50} / \mathrm{SiO}_{2}$ catalysts both presented a mixture of fcc and bcc phases, implying the presence of nanoparticles with very different compositions, in particular Fe-rich nanoparticles [17]. These disparities may make the analysis and interpretation of catalytic data tricky, as each class of nanoparticles may display its own catalytic performances. Catalysts are often characterized by $\mathrm{XRD}$, which provides at best an average view over the composition of the nanoparticles, as the XRD peaks position changes within a very small range of a few tenths of degree upon modifying the metals content across the whole $\gamma$ domain. The composition of individual nanoparticles is not always studied nor reported. Especially for IWI preparations, scanning transmission electron microscopy (STEM)-EDX mappings [34] are necessary to confirm the alloying between the two metals within bimetallic nanoparticles (Figure 2B), and the absence of heterogeneities of composition.

\subsubsection{Sol-Gel Routes}

In sol-gel routes, a sol is formed by adding an acid to a solution containing an alkoxide precursor of the support (for example, aluminium isopropoxide when alumina is selected as the future support). After addition of Fe and Ni precursors (such as nitrates or acetates), the system gradually evolves 
towards the formation of a gel containing the three metallic elements [12,13,35,36]. Systems with an ordered porosity can be prepared by addition of a porogen and slow evaporation of the solvent (evaporation-induced self-assembly, EISA) [36]. Calcination and reduction lead to Ni-Fe alloyed nanoparticles dispersed onto the support.

Because of their early insertion in what will become the catalyst support, the resulting solid can be considered as more homogeneous than in the case of IWI. But phases obtained upon calcination are a mixture of several metal oxides, some of them being formed by insertion of the Fe and Ni ions into the support: $\mathrm{NiAl}_{2} \mathrm{O}_{4}, \mathrm{FeAl}_{2} \mathrm{O}_{4}, \mathrm{AlFeO}_{3}[12,13,35]$. Metal ions present in spinel and perovskite phases are difficult to extract and reduce, thus requiring a high reduction temperature; for example, a temperature of $700{ }^{\circ} \mathrm{C}$ has been selected by Hwang et al. [12,13], and Liu et al. [36]. However, sintering is limited upon reduction. The average particle size is reported to be smaller than $8 \mathrm{~nm}$ with narrow size distributions (Figure 3) [12,13,36], and in this respect sol-gel routes appear to provide a better control than IWI. The drawback of the sol-gel route is the cost of the alkoxide precursor, and its sensitivity to humidity.
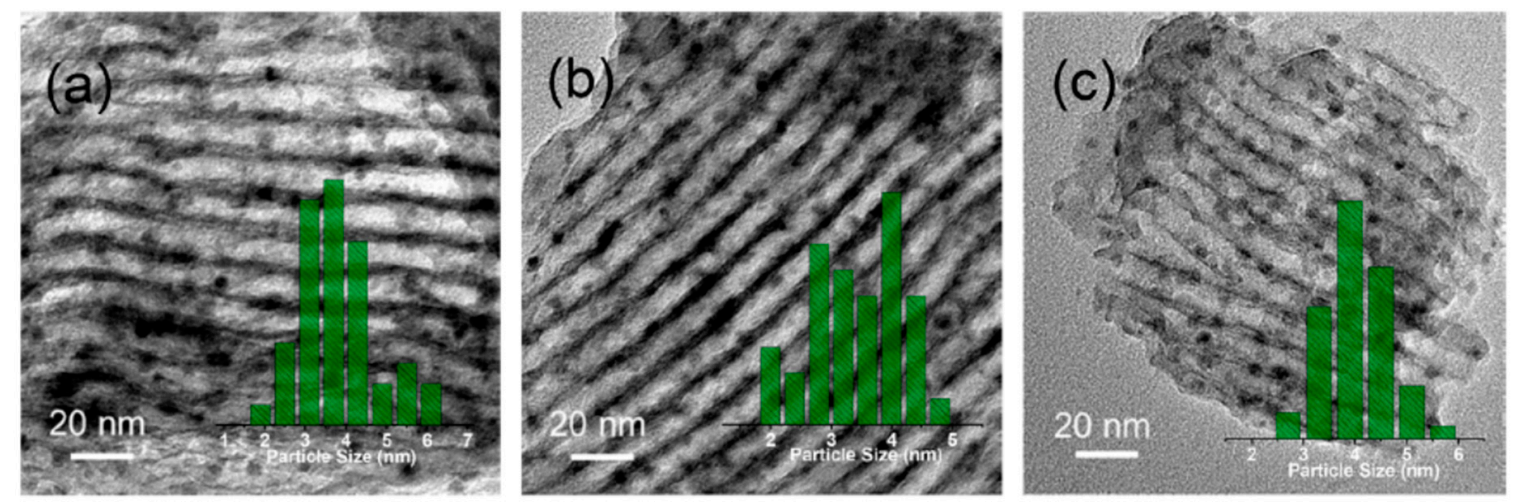

Figure 3. TEM images and size histograms of $\mathrm{Ni}(-\mathrm{Fe}) /$ ordered mesoporous alumina (OMA) catalysts prepared by the evaporation-induced self-assembly (EISA) method and reduced at $700{ }^{\circ} \mathrm{C}:(\mathbf{a}) 8 \mathrm{wt} \%$ $\mathrm{Ni} / \mathrm{OMA}$; (b) 9 wt $\% \mathrm{Ni}_{91} \mathrm{Fe}_{9} / \mathrm{OMA}$; (c) $9 \mathrm{wt} \% \mathrm{Ni}_{84} \mathrm{Fe}_{16} / \mathrm{OMA}$. Reprinted with permission from Reference [36]. Copyright 2017 American Chemical Society.

\subsubsection{Co-Precipitation and Deposition-Precipitation}

A procedure that associates a simple implementation like IWI, and the early insertion of the two metals in the solid precursor as is achieved with the sol-gel route, is co-precipitation. Layered double hydroxides of the hydrotalcite-type can be conveniently obtained by basification, with ammonia or carbonate ions, of an aqueous solution containing $\mathrm{Fe}, \mathrm{Ni}, \mathrm{Al}$ and $\mathrm{Mg}$ precursors [8,37-39]. This method has become favored for the preparation of $\mathrm{Al}_{2} \mathrm{O}_{3}$-supported catalysts for catalytic reforming or $\mathrm{CO} / \mathrm{CO}_{2}$ methanation $[3-5,8,16]$. Co-precipitation has also been reported in association with an organic substrate like melamine, which after carbonization allows protection of the metal nanoparticles [40]. Ni-Fe particles of homogeneous size (3-7 nm) and composition are formed upon reduction (Figure 4), but, as in the case of the sol-gel route, a high temperature, up to $800^{\circ} \mathrm{C}$, is sometimes necessary for complete reduction [8].

Deposition-precipitation (DP) is a related preparation method that leads to the deposition of a Fe- and Ni-containing compound either onto a pre-existing support, or as the result of dissolution-reprecipitation reactions involving the support. Nickel and iron salts are introduced into an aqueous solution with the support, such as $\mathrm{SiO}_{2}$ or $\mathrm{Al}_{2} \mathrm{O}_{3}$, and the $\mathrm{pH}$ of the solution is progressively increased by addition of a base, till precipitation takes place. A homogeneous increase of $\mathrm{pH}$ can be obtained by decomposing urea above $80{ }^{\circ} \mathrm{C}$. Ni-Fe nanoparticles are formed upon reduction in $\mathrm{H}_{2}$. 

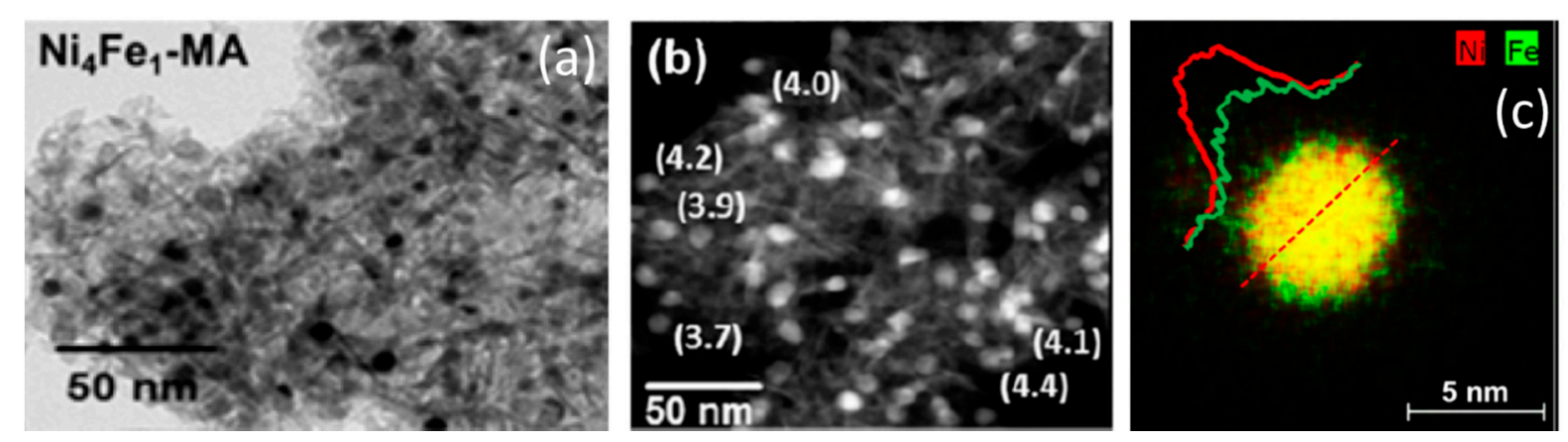

Figure 4. TEM characterization of a $10 \mathrm{wt} \% \mathrm{Ni}_{80} \mathrm{Fe}_{20} /$ magnesium aluminate catalyst prepared by co-precipitation and reduced at $800{ }^{\circ} \mathrm{C}$ : (a) Bright-field TEM image; (b) STEM-EDX analysis, including the Ni/Fe atomic ratio for individual nanoparticles (nominal ratio: 4); (c) linear STEM-EDX scanning across one Ni-Fe nanoparticle. Reprinted with permission from Reference [8]. Copyright 2017 American Chemical Society.

Mutz et al. have used Ni(II) and Fe(III) nitrates as precursors for a DP process with urea on alumina [41]. A narrow distribution around a small average size $(3.9 \mathrm{~nm})$ and a high homogeneity of chemical composition $\left(\mathrm{Ni}_{75} \mathrm{Fe}_{25}\right)$ were achieved after reduction at $500{ }^{\circ} \mathrm{C}$. Because of the different valences of the ions, iron (III) hydroxide should deposit at a lower $\mathrm{pH}$ than nickel (II) and iron (II) hydroxides ( $\mathrm{pH} 2-3$ vs. 5-6 for dilute solutions). The homogeneity of the solid obtained by Mutz et al. can be attributed to the use of alumina as support, and to the likely precipitation not of a hydroxide, but of an Al-based hydrotalcite phase apt to accommodate $\mathrm{Fe}^{3+}$ ions.

Using a different support may require a change of strategy. In order to avoid the early, separate precipitation of Fe(III)-containing compounds, precursors to Fe-rich particles, Shi et al. rather selected $\mathrm{Ni}(\mathrm{II})$ and $\mathrm{Fe}$ (II) sulfates for the preparation of $\mathrm{Ni}-\mathrm{Fe} / \mathrm{SiO}_{2}$ catalysts, and eliminated all sources of oxidation from the preparation protocol (use of sulfuric acid instead of nitric acid, degassing of the solution by Ar) [28]. After $22 \mathrm{~h}$ of DP with urea under inert atmosphere, the resulting solid was a 1:1 ill-organized (Ni(II), Fe(II)) phyllosilicate containing a slight excess of $\mathrm{Ni}$ compared with the initial composition of the solution. Iron ions would later oxidize in air to $\mathrm{Fe}(\mathrm{III})$, though without any consequence on the subsequent formation of the Ni-Fe particles.

Like on co-precipitated catalysts, reduced Ni-Fe nanoparticles on catalysts prepared by DP present a size often smaller than on catalysts prepared by IWI $(3-7 \mathrm{~nm})[28,41,42]$. When the reduction temperature is low, the metals may not be fully reduced, and a high reduction temperature may be necessary because of the presence of phases formed between metal and support (silicates). Though an increase of the particle size has been reported (up to $15.2 \mathrm{~nm}$ [7]), nanoparticles prepared by DP can sustain a high reduction temperature without undergoing severe sintering. Shi et al. have shown that on silica, the increase of the average Ni-Fe particle size is moderate between 500 and $700{ }^{\circ} \mathrm{C}$ (5.1 vs. $5.4 \mathrm{~nm}$ ), without major change in the size histogram. The composition of the particles was reported to be homogeneous: The standard deviation calculated from EDX measurements carried out on a population of individual particles was 8 at $\% \mathrm{Fe}$ for $\mathrm{Ni}_{69} \mathrm{Fe}_{31}$ nanoparticles, and no monometallic or Fe-rich particles were detected [28].

Alternatively, van de Loosdrecht et al. prepared Ni-Fe catalysts by implementing the deposition-precipitation of iron-nickel cyanide complexes onto a $\mathrm{TiO}_{2}$ support [43,44]. A potassium iron cyanide solution was injected into a suspension of $\mathrm{TiO}_{2}$ in a solution of nickel nitrate kept at $\mathrm{pH} 5$. The resulting solid was calcined in air at $300{ }^{\circ} \mathrm{C}$ to remove the cyanide ligands. The total reduction of the metals was reached only at $900{ }^{\circ} \mathrm{C}$ according to temperature-programmed reduction (TPR) profiles, because of the formation of nickel or iron titanate. The size of the Ni-Fe particles after reduction of $900^{\circ} \mathrm{C}$, calculated from XRD data, turned out to be quite large, $15-20 \mathrm{~nm}$. Co-precipitation of oxalates over a melamine substrate has been recently described, leading to $38 \mathrm{~nm}$ bimetallic nanoparticles after carbothermal reduction [27]. 
In conclusion, the phases obtained after incipient wetness impregnation and calcination are based on the two monometallic metal oxides, which shows that the two metals are not associated at this stage of the preparation, but doping of the monometallic oxides by the other metal is likely to occur. Phases detected after calcination when sol-gel or co-precipitation methods are implemented are a mixture of monometallic and mixed oxides, some of them involving the support $\left(\mathrm{NiAl}_{2} \mathrm{O}_{4}, \mathrm{FeAl}_{2} \mathrm{O}_{4}\right)$, which may require a high temperature to achieve complete reduction. Ni-Fe nanoparticles prepared by procedures based on co-precipitation exhibit a high level of homogeneity in terms of size and composition. The particle size obtained by sol-gel route, co-precipitation or deposition-precipitation is usually smaller, and the size distribution narrower, than those obtained by incipient wetness impregnation, which for the sake of convenience still remains a standard procedure that can be applied to any porous support.

\subsection{Reducibility of Ni-Fe Supported Oxidic Phases and Formation of Ni-Fe Nanoparticles}

The reduction stage is crucial to form $\mathrm{Ni}-\mathrm{Fe}$ nanoparticles since metal oxides do not bear the active sites for hydrogenation catalysis. Globally speaking, $\mathrm{Fe}_{2} \mathrm{O}_{3}$ and $\mathrm{NiO}$ reduce in the lower temperature range (below $500{ }^{\circ} \mathrm{C}$ ) if the interaction between the oxidic phases and the support surface is weak (as is the case for IWI when oxidic particles are large), and higher temperatures are required for reduction completion (up to $900^{\circ} \mathrm{C}$ ) when metal ions form oxidic phases with the support (IWI, sol-gel route, DP). In one of the earliest studies on the reducibility of the Ni-Fe system, Unmuth et al. have investigated by TPR the reducibility of $\mathrm{Fe}_{2} \mathrm{O}_{3}$ and $\mathrm{NiO}$ on $\mathrm{SiO}_{2}$ independently, with different temperature rates [23]. Two stages of reduction were evidenced for iron oxide: An " $\alpha$ peak" was assigned to the reduction of $\mathrm{Fe}_{2} \mathrm{O}_{3}$ to $\mathrm{Fe}_{3} \mathrm{O}_{4}$ at about $320^{\circ} \mathrm{C}$, while a " $\beta$ peak" was assigned to the reduction of $\mathrm{Fe}_{3} \mathrm{O}_{4}$ to $\mathrm{Fe}$ at about $450{ }^{\circ} \mathrm{C}$. The reduction of bulk $\mathrm{NiO}$ to $\mathrm{Ni}$ was found to take place at about $300^{\circ} \mathrm{C}$. A shoulder on the peak was thought to be characteristic of very small particles of oxide strongly interacting with silica. Therefore, Fe was found to be the more difficult metal to reduce of the two, notwithstanding particle size and support effects that may change the game, and make a phenomenological interpretation only based on TPR profiles difficult.

The presence of $\mathrm{Ni}$ on bimetallic $\mathrm{Ni}-\mathrm{Fe}$ catalysts is widely considered to favor the reduction of Fe, even at low Ni contents. As early as 1982, Brown et al. published a series of TPR profiles evidencing the gradual shifts to lower temperatures of reduction peaks when increasing the Ni content of co-precipitated Ni-Fe catalysts, with a significant effect noticed for $\mathrm{Ni}_{40} \mathrm{Fe}_{60}$ (lower limit of the fcc domain) and Ni-richer formulations (Figure 5A) [45]. In the Fe-rich domain, Li et al. found that while the reduction temperature for monometallic Fe was $570{ }^{\circ} \mathrm{C}$, a small shift to $550{ }^{\circ} \mathrm{C}$ appeared for the $\mathrm{Ni}_{1} \mathrm{Fe}_{99}$ formulation, and the reduction temperature for the $\mathrm{Ni}_{13} \mathrm{Fe}_{87}$ formulation was lowered to $510{ }^{\circ} \mathrm{C}[38]$.

We will detail here only a few examples from the literature, selected to show that this trend is verified for a variety of solids. A dramatic decrease of reduction temperature for $\mathrm{Ni}-\mathrm{Fe} / \mathrm{SiO}_{2}$ catalysts compared with $\mathrm{Fe} / \mathrm{SiO}_{2}$ was found by $\mathrm{Yu}$ et al. [46]. A first reduction peak at $260-510{ }^{\circ} \mathrm{C}$ for $\mathrm{Fe} / \mathrm{SiO}_{2}$ was attributed to the reduction of $\mathrm{Fe}_{2} \mathrm{O}_{3}$ to $\mathrm{Fe}_{3} \mathrm{O}_{4}$ and a second peak above $930{ }^{\circ} \mathrm{C}$ was ascribed to the reduction of $\mathrm{Fe}_{3} \mathrm{O}_{4}$ to $\mathrm{Fe}$, but should most likely be attributed to the reduction of iron silicates (Figure $5 \mathrm{~B}$ ). The main reduction peak at about $390{ }^{\circ} \mathrm{C}$ for Ni/SiO${ }_{2}$ was assigned to the reduction of $\mathrm{NiO}$ to Ni. In contrast with $\mathrm{Fe} / \mathrm{SiO}_{2}, \mathrm{Ni}-\mathrm{Fe} / \mathrm{SiO}_{2}$ calcined solids containing the same amount of $\mathrm{Ni}$ $(8 \mathrm{wt} \%)$ and increasing amounts of $\mathrm{Fe}$ did not display any reduction peak above $530{ }^{\circ} \mathrm{C}$, implying the simultaneous reduction of iron oxide and nickel oxide even when $\mathrm{Ni}$ was the minor metal.

In the case of systems in which the two metals are initially inserted in an oxidic matrix, Oemar et al. have studied the reducibility of perovskites containing Fe and Ni. No peak was observed on the TPR profile of $\mathrm{LaFeO}_{3}$ up to $900^{\circ} \mathrm{C}$ (Figure 5C) [47]. However, a reduction peak appeared at $850{ }^{\circ} \mathrm{C}$ after adding a small amount of $\mathrm{Ni}\left(\mathrm{LaFe}_{0.8} \mathrm{Ni}_{0.2} \mathrm{O}_{3}\right)$, which indicates that some chemical interplay existed between $\mathrm{Ni}$ and $\mathrm{Fe}$ ions inside the structure. The peak shifted to lower temperatures, down to $540{ }^{\circ} \mathrm{C}$, when further increasing the $\mathrm{Ni}$ content up to $\mathrm{LaNiO}_{3}$. 


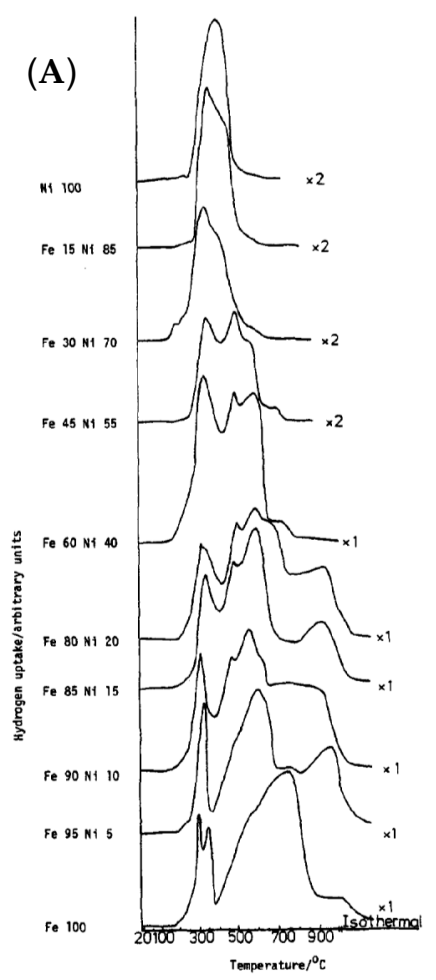

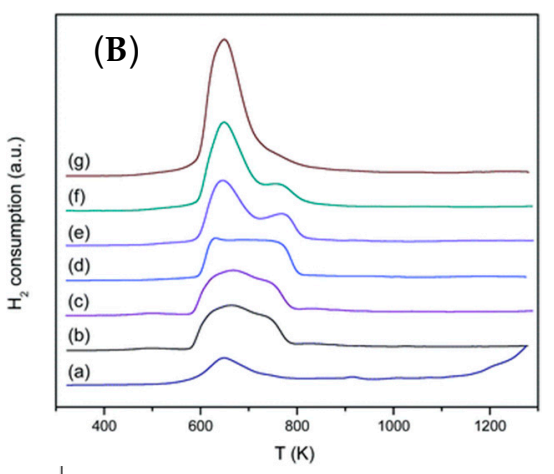

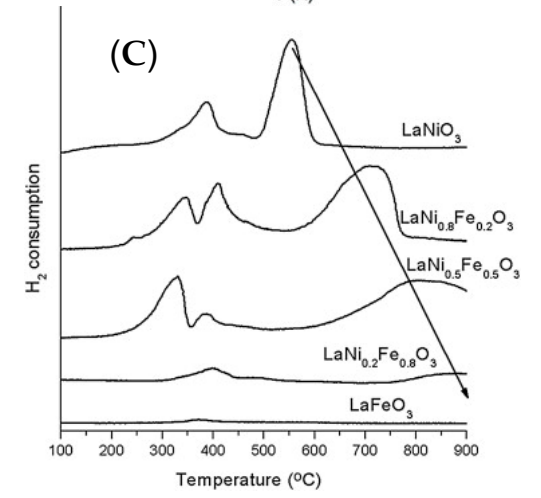

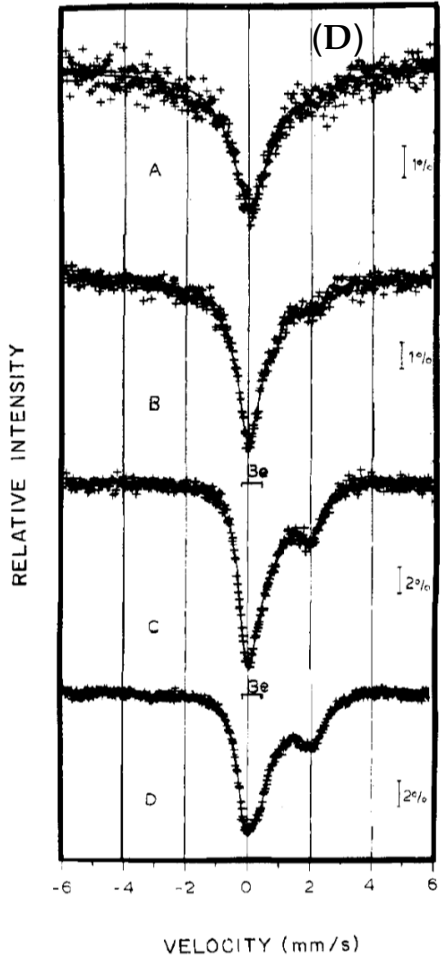

Figure 5. (A) Temperature-reduction profiles of Ni-Fe catalysts prepared by co-precipitation, as a function of the Fe and Ni contents. Reprinted from Reference [45], copyright 1982, with permission from Elsevier; (B) temperature-reduction profiles of $8-16 \mathrm{wt} \% \mathrm{Ni}-\mathrm{Fe} / \mathrm{SiO}_{2}$ catalysts prepared by co-impregnation: (a) $\mathrm{Fe} / \mathrm{SiO}_{2}$, (b) $\mathrm{Ni} / \mathrm{SiO}_{2}$, (c) $\mathrm{Ni}_{94} \mathrm{Fe}_{6} / \mathrm{SiO}_{2}$, (d) $\mathrm{Ni}_{89} \mathrm{Fe}_{11} / \mathrm{SiO}_{2}$, (e) $\mathrm{Ni}_{80} \mathrm{Fe}_{20} / \mathrm{SiO}_{2}$, (f) $\mathrm{Ni}_{67} \mathrm{Fe}_{33} / \mathrm{SiO}_{2}$, (g) $\mathrm{Ni}_{50} \mathrm{Fe}_{50} / \mathrm{SiO}_{2}$. Republished with permission of the Royal Society of Chemistry, from Reference [46]; permission conveyed through Copyright Clearance Center, Inc.; (C) temperature-reduction profiles of $\mathrm{LaFeO}_{3}, \mathrm{LaNiO}_{3}$ and Ni-Fe-containing perovskites. Reprinted from Reference [47], copyright 2013, with permission from Elsevier; (D) ${ }^{57} \mathrm{Fe}$ Mössbauer spectra recorded at room temperature after reduction at $440{ }^{\circ} \mathrm{C}$ of, from top to bottom: $6.5 \mathrm{wt} \% \mathrm{Ni}_{92} \mathrm{Fe}_{8} / \mathrm{TiO}_{2}$ (W), $5.7 \mathrm{wt} \% \mathrm{Ni}_{90} \mathrm{Fe}_{10} / \mathrm{TiO}_{2}(\mathrm{~S}), 6.1 \mathrm{wt} \% \mathrm{Ni}_{95} \mathrm{Fe}_{5} / \mathrm{Al}_{2} \mathrm{O}_{3}(\mathrm{~S}), 6.6 \mathrm{wt} \% \mathrm{Ni}_{92} \mathrm{Fe}_{8} / \mathrm{Al}_{2} \mathrm{O}_{3}$ (W). (S) and (W) refer to the $\mathrm{pH}$ of the co-impregnation solutions, 0 and 1, respectively. Reprinted with permission from Reference [48]. Copyright 1984 American Chemical Society.

The reducibility of the $17 \mathrm{wt} \% \mathrm{Ni}_{75} \mathrm{Fe}_{25} / \mathrm{Al}_{2} \mathrm{O}_{3}$ catalyst prepared by DP by Mutz et al. was investigated by TPR and compared to the profile obtained for a monometallic Ni catalyst [41]. The $\mathrm{H}_{2}$ consumption profile of the Ni catalyst revealed one main peak at $573{ }^{\circ} \mathrm{C}$, referring to the reduction of $\mathrm{NiO}$ to metallic $\mathrm{Ni}$. The shoulder around $750^{\circ} \mathrm{C}$ was ascribed to smaller $\mathrm{NiO}$ particles exhibiting stronger interactions with the alumina support. The main reduction peak shifted to lower temperatures for the $\mathrm{Ni}_{75} \mathrm{Fe}_{25} / \mathrm{Al}_{2} \mathrm{O}_{3}$ catalyst (from 573 to $555^{\circ} \mathrm{C}$ ). The two reduction peaks of $\mathrm{Ni}_{75} \mathrm{Fe}_{25} / \mathrm{Al}_{2} \mathrm{O}_{3}$ were assigned to the reduction of $\mathrm{Fe}_{2} \mathrm{O}_{3}$ to $\mathrm{Fe}_{3} \mathrm{O}_{4}$ in the ternary $\mathrm{Al}-\mathrm{Ni}-\mathrm{Fe}$ oxide $\left(350^{\circ} \mathrm{C}\right)$, and to the reduction of $\mathrm{Fe}_{3} \mathrm{O}_{4}$ to $\mathrm{Fe}$ and $\mathrm{NiO}$ to $\mathrm{Ni}\left(555^{\circ} \mathrm{C}\right)$.

More recently, Shi et al. followed by in situ X-ray absorption and ${ }^{57} \mathrm{Fe}$ Mössbauer spectroscopies the kinetics of reduction of a 1:1 (Fe(III, Ni(II)) phyllosilicate formed by DP with urea [28]. They could evidence a succession of stages that confirms the classical interpretations of TPR thermograms for Ni-Fe systems: Reduction of $\mathrm{Fe}(\mathrm{III})$ to $\mathrm{Fe}(\mathrm{II})$ between 275 and $360^{\circ} \mathrm{C}$; between 360 and $500^{\circ} \mathrm{C}$, simultaneous reduction of $\mathrm{Ni}(\mathrm{II})$ to $\mathrm{Ni}(0)$ and $\mathrm{Fe}(\mathrm{II})$ to $\mathrm{Fe}(0)$, which confirms the decisive role of $\mathrm{Ni}$ in the reduction of Fe when the two metals are closely associated in the solid; completion of the reduction of Fe(II) to $\mathrm{Fe}(0)$ between 500 and $700{ }^{\circ} \mathrm{C}$, and migration of metallic Fe into the core of the just-formed $\mathrm{Ni}-\mathrm{Fe}$ fcc nanoparticles. 
It derives from these results that the higher the reduction temperature, the more $\mathrm{Ni}-\mathrm{Fe}$ alloyed nanoparticles are formed and the higher the extent of Fe reduction, with a lower risk of particle sintering when metal particles are stabilized by interactions with the support, such as for sol-gel or precipitations routes. Globally speaking, a $\mathrm{SiO}_{2}$ or a $\mathrm{TiO}_{2}$ support provides a higher reducibility compared with an $\mathrm{Al}_{2} \mathrm{O}_{3}$ support, because of the easy formation of spinels on $\mathrm{Al}_{2} \mathrm{O}_{3}$, in which case some Ni- or Fe-containing phases have been reported to remain unreduced even after reduction at $900{ }^{\circ} \mathrm{C}$ [45]. Evidence for this support effect was clearly shown by Jiang et al. using four catalysts prepared by co-impregnation in similar conditions, two on $\mathrm{TiO}_{2}$ and two on $\mathrm{Al}_{2} \mathrm{O}_{3}$ [48]. The two $\mathrm{Ni}-\mathrm{Fe} / \mathrm{TiO}_{2}$ catalysts appeared as almost fully reduced at $440{ }^{\circ} \mathrm{C}$, as their ${ }^{57} \mathrm{Fe}$ Mössbauer spectrum presented the singlet peak characteristic of $\mathrm{Ni}-\mathrm{Fe}$ alloys, while their $\mathrm{Ni}-\mathrm{Fe} / \mathrm{Al}_{2} \mathrm{O}_{3}$ counterparts, though prepared in the same conditions, still contained a significant amount of unreduced $\mathrm{Fe}^{2+}$ ions, as shown by the signal at $2 \mathrm{~mm} / \mathrm{s}$, that constitutes one part of the quadrupole split component associated to these ions (Figure 5D). The late reduction of Fe and the trapping of unreduced Fe ions inside oxidic phases may be the source of further variance of metal proportions within the $\mathrm{Ni}-\mathrm{Fe}$ particles, compared with the nominal formulation of the catalyst.

\section{Ni-Fe Catalysts for the Hydrogenation of Organic Molecules}

Since the 1980s, several authors have noted that Ni-Fe bimetallic catalysts are interesting candidates for the selective hydrogenation of organic molecules, with gains in terms of activity and selectivity compared to $\mathrm{Ni}$ catalysts. In this section, we will aim at identifying the main characteristics of $\mathrm{Ni}-\mathrm{Fe}$ catalysts in terms of catalytic performances, and if specific formulations have consistently provided promising results.

\subsection{Hydrogenation of Double and Triple Carbon-Carbon Bonds}

One of the first papers in which Ni-Fe catalysts have been tested for the hydrogenation of organic molecules concerns the hydrogenation of ethylene to ethane. Matsuyama et al. compared three families of unsupported Ni-based alloys, $\mathrm{Ni}-\mathrm{Cu}, \mathrm{Ni}-\mathrm{Fe}$ and $\mathrm{Ni}-\mathrm{Co}$ [20]. At $0^{\circ} \mathrm{C}, \mathrm{Ni}-\mathrm{Fe}$ alloys from the fcc domain, reduced at $385^{\circ} \mathrm{C}$, provided the highest normalized rate of reaction: $1 \mathrm{~min}^{-1} \mathrm{~m}^{-2}$ for the $\mathrm{Ni}_{50} \mathrm{Fe}_{50}$ and $\mathrm{Ni}_{60} \mathrm{Fe}_{40}$ bulk formulations, three times more than Fe-rich bcc phases and monometallic $\mathrm{Ni}$ (Figure 6A). We will come back to this seminal paper and to Figure 6A in Section 4.4, as they give an important key to understand the reactivity of the Ni-Fe system.

The hydrogenation of propyne was carried out by Kojima et al. on unsupported Ni-Fe alloys prepared by the reduction of a mixed hydroxide obtained by co-precipitation from an ethylene glycol solution [49]. Ni-Fe catalysts were activated under $\mathrm{H}_{2}$ at $400{ }^{\circ} \mathrm{C}$ before reaction. The catalytic performances were measured between room temperature and $160^{\circ} \mathrm{C} . \mathrm{Ni}_{70} \mathrm{Fe}_{30}$ alloys appeared as less active than monometallic $\mathrm{Ni}$ (the reaction rate normalized per $\mathrm{m}^{2}$ decreased by a factor 10 ), but a dramatic decrease of selectivity to propane, and correlated increase of selectivity to propene, were noted, even at full conversion (Figure 6B). Decreasing the Ni content led to a slight decrease of the normalized reaction rate, but the selectivity to the alkene, propene, was maintained above $60 \%$ over the whole temperature range. Reaction orders did not change compared with $\mathrm{Ni}$, but the activation energy was seen to decrease from $49 \mathrm{~kJ} \mathrm{~mol}^{-1}$ for Ni, to $36 \mathrm{~kJ} \mathrm{~mol}^{-1}$ for $\mathrm{Ni}_{46} \mathrm{Fe}_{64}$. The increase to $42 \mathrm{~kJ}$ $\mathrm{mol}^{-1}$ noted for $\mathrm{Ni}_{33} \mathrm{Fe}_{67}$ can be attributed to the presence of bcc Fe-rich and fcc Ni-rich particles for this formulation, the only one that falls in the de-mixing domain (Section 2.1).

A quantitative hydrogenation of the alkene or alkyne function in styrene and phenylacetylene to ethylbenzene has been obtained by Chieffi et al. at $50{ }^{\circ} \mathrm{C}$ in ethanol, using a $56 \mathrm{wt} \% \mathrm{Ni}_{58} \mathrm{Fe}_{42} / \mathrm{carbon}$ catalyst prepared by impregnation of cellulose and carbothermal reduction (alloy particle size: 20-30 nm, XRD, TEM) [34]. No deactivation was observed over a period of $80 \mathrm{~h}$. This was attributed to the protection of the metal particles by carbon layers.

Finally, using $56 \mathrm{wt} \% \mathrm{Ni}_{58} \mathrm{Fe}_{42} /$ carbon and $25 \mathrm{wt} \% \mathrm{Ni}_{75} \mathrm{Fe}_{25} / \mathrm{CeO}_{2}$ catalysts, respectively, a high activity was achieved for the selective hydrogenation of $\mathrm{C}=\mathrm{C}$ bonds from two more complex molecules, 
$\alpha$-terpinene [34] and 2-cyclohexen-1-one [26] at a respective reaction temperature of $125^{\circ} \mathrm{C}$ (conversion of $\alpha$-terpinene: $99 \%$, selectivity to 1-isopropyl-4-methylcyclohexene: $56 \%$ ) and $130{ }^{\circ} \mathrm{C}$ (conversion of 2-cyclohexen-1-one: $100 \%$, selectivity to cyclohexanone: $98 \%$ ).

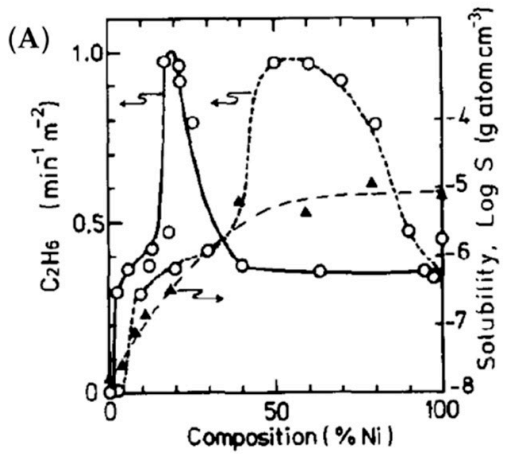

(B)

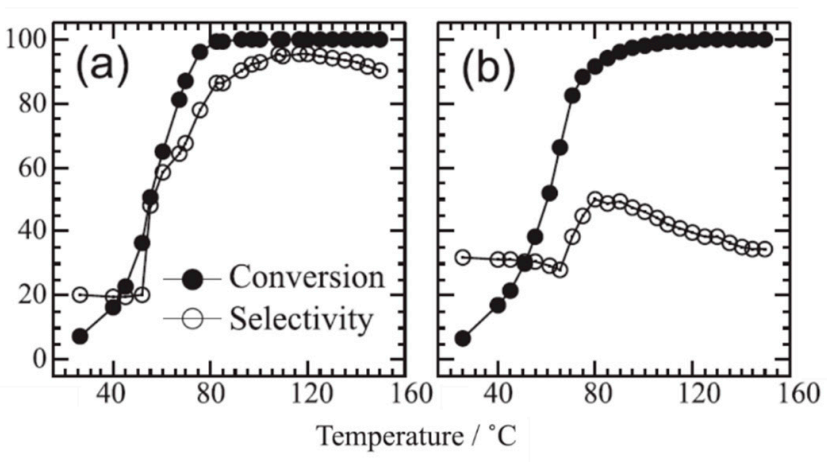

Figure 6. (A) Normalized rate of hydrogenation of ethylene as a function of the bulk composition (circles, dotted line) and of the surface composition (circles, full line) of Ni-Fe alloys; solubility of hydrogen in the alloys (triangles). Reprinted from Reference [20], copyright 1986, with permission from Elsevier; (B) conversion and selectivity to propane of (a) $\mathrm{Ni}$ and (b) a $\mathrm{Ni}_{70} \mathrm{Fe}_{30}$ alloy, in the hydrogenation of propyne. Reprinted from Reference [49].

\subsection{Selective Hydrogenation of Oxygenates}

The largest range of organic molecules tested for selective hydrogenation on Ni-Fe catalysts is the family of oxygenates: Ketones, aldehydes, acids, esters, monosaccharides. Given their specificities, furanic compounds will be presented separately in Section 3.6.

Table 1 summarizes the results obtained by Chieffi et al. [34], and Putro et al. [26], on a variety of oxygenates, including the reaction conditions, conversions and selectivities. The characteristics of the $\mathrm{Ni}-\mathrm{Fe}$ catalyst used by Chieffi et al. have been presented above (Section 3.1). Putro et al. prepared both unsupported and supported Ni-Fe catalysts by co-precipitation followed by a hydrothermal treatment and reduction between 300 and $500{ }^{\circ} \mathrm{C}$. XRD results were interpreted on the basis of the formation of both ordered $\mathrm{Ni}_{3} \mathrm{Fe}$ and $\mathrm{Ni}$ nanoparticles (average crystallite size for unsupported $\mathrm{Ni}_{67} \mathrm{Fe}_{33}: 16 \mathrm{~nm}$, XRD; particle size on $\mathrm{TiO}_{2}$-supported systems: $18-22 \mathrm{~nm}$, TEM). Support effects will be detailed below. Only one Ni-Fe formulation was tested in each work.

Table 1 shows that while the reduction of aromatic aldehydes to aromatic alcohols is quantitative, the results in the hydrogenation of unsaturated carbonyls are contrasted and seem to depend on the relative position of the $\mathrm{C}=\mathrm{C}$ and the $\mathrm{C}=\mathrm{O}$ bonds. Conversion and selectivity to the unsaturated alcohols are often high for molecules in which the $\mathrm{C}=\mathrm{C}$ and $\mathrm{C}=\mathrm{O}$ bonds are not close to each other, and they are significantly lower for $\alpha, \beta$-unsaturated aldehydes or ketones for which the hydrogenation of the $C=C$ bond is sometimes favored.

Chieffi et al. have also explored the hydrogenation of levulinic acid to $\gamma$-valerolactone, and of monosaccharides (glucose, xylose) to the corresponding polyols (sorbitol, xylitol), with in this case a quantitative conversion in water, for glucose concentrations comprised of between 0.1 and $0.5 \mathrm{~mol} \mathrm{~L}^{-1}$. This result confirms the early findings by Gallezot et al. on Fe-promoted Raney Ni (six-fold increase of initial reaction rate when comparing $\mathrm{Ni}_{83} \mathrm{Fe}_{17}$ to $\mathrm{Ni}$ catalysts), which were troubled though by the leaching of $\mathrm{Fe}$ into the $2.3 \mathrm{~mol} \mathrm{~L}^{-1}$ aqueous solution of glucose upon successive runs [50]. Increasing the concentration to $1 \mathrm{~mol} \mathrm{~L}^{-1}$ was indicated by Chieffi et al. to reduce the sorbitol yield to $40 \%$.

The role of the oxidic support $\left(\mathrm{Al}_{2} \mathrm{O}_{3}, \mathrm{TiO}_{2}, \mathrm{CeO}_{2}\right)$ on the hydrogenation of 2-cyclohexen-1-one as investigated by Putro et al. cannot be analyzed simply, as selectivities have been compared at very different conversions [26]. The least active catalysts, supported on $\mathrm{Al}_{2} \mathrm{O}_{3}$ and $\mathrm{TiO}_{2}$, would favor the hydrogenation to 2-cyclohexen-1-ol at low conversion (hydrogenation of the ketone function), 
while the most active catalysts, unsupported or supported on $\mathrm{CeO}_{2}$, would favor the formation of cyclohexanone at high conversion (hydrogenation of the $\mathrm{C}=\mathrm{C}$ bond).

Table 1. Hydrogenation of oxygenates using a $56 \mathrm{wt} \% \mathrm{Ni}_{58} \mathrm{Fe}_{42} /$ carbon catalyst prepared by carbothermal reduction [34] or a $25 \mathrm{wt} \% \mathrm{Ni}_{67} \mathrm{Fe}_{33} / \mathrm{TiO}_{2}$ catalyst reduced at $300{ }^{\circ} \mathrm{C}$ [26]: Experimental conditions, conversion (Conv.) and selectivity (S) in the mentioned product.

Reference

The influence of the Ni-Fe proportions on catalytic performances were reported in the first paper published on the application of $\mathrm{Ni}-\mathrm{Fe}$ catalysts to the hydrogenation of oxygenated functions. Kumbhar et al. found that the highest activity for the hydrogenation of acetophenone to $\alpha$-phenylethanol in methanol at $135^{\circ} \mathrm{C}$ was obtained with a $20 \mathrm{wt} \% \mathrm{Ni}_{75} \mathrm{Fe}_{25} / \mathrm{SiO}_{2}$ catalyst, prepared by co-impregnation and reduced at $450{ }^{\circ} \mathrm{C}$ (particle size determined by the Scherrer equation: $13 \mathrm{~nm}$ ) (Figure 7a) [17]. However, the comparison with $\mathrm{Ni} / \mathrm{SiO}_{2}$ is ambiguous, as the Ni catalyst presents larger Ni nanoparticles, and the ratio between the reaction rates is similar to the ratio between the two metal dispersions. 
The lack of activity of the other $\mathrm{Ni}-\mathrm{Fe}$ catalysts is also difficult to comment, because unlike $\mathrm{Ni}_{75} \mathrm{Fe}_{25} / \mathrm{SiO}_{2}$, the catalysts bear a mixture of bcc and fcc particles. Hydrogenolysis to ethylbenzene is mentioned to occur above $70 \%$ of conversion whatever the catalyst formulation.
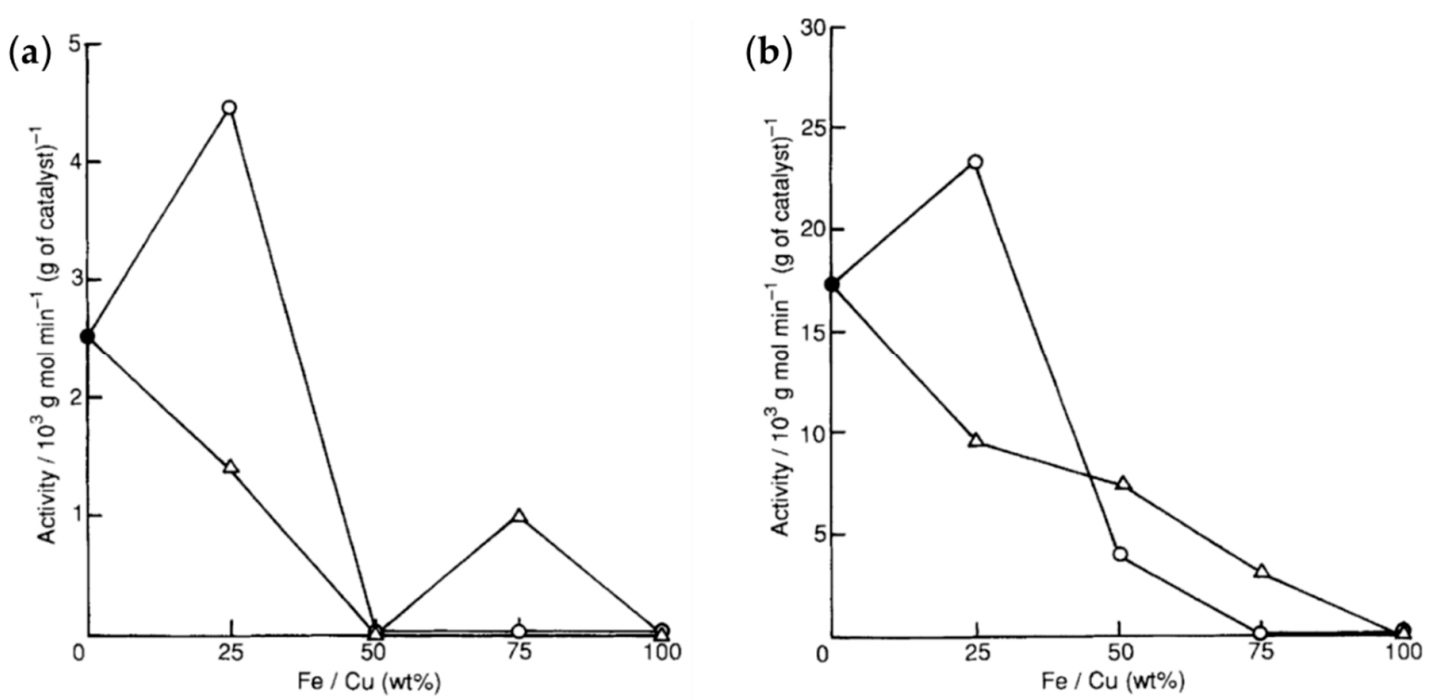

Figure 7. Reaction rates of $20 \mathrm{wt} \% \mathrm{Ni}-\mathrm{Fe} / \mathrm{SiO}_{2}$ catalysts (circles) as a function of Fe proportion in (a) the hydrogenation of acetophenone $\left(\mathrm{T}=135^{\circ} \mathrm{C}, \mathrm{P}\left(\mathrm{H}_{2}\right)=58\right.$ bar, solvent: Ethanol $)$ and $(\mathbf{b})$ the hydrogenation of benzonitrile $\left(\mathrm{T}=150{ }^{\circ} \mathrm{C}, \mathrm{P}\left(\mathrm{H}_{2}\right)=34\right.$ bar, solvent: Methanol). Triangles correspond to $\mathrm{Ni}-\mathrm{Cu} / \mathrm{SiO}_{2}$ catalysts. Republished with permission of the Royal Society of Chemistry, from Reference [17]; permission conveyed through Copyright Clearance Center, Inc.

The hydrogenation of acids and esters has been described in a few papers. Stearic acid was selectively hydrogenated into stearic alcohol in dioxane at $250{ }^{\circ} \mathrm{C}$ on $67-88 \mathrm{wt} \% \mathrm{Ni}-\mathrm{Fe} /$ carbon catalysts prepared by co-precipitation of metal oxalates on melamine followed by carbothermal reduction at $800^{\circ} \mathrm{C}$ under $\mathrm{N}_{2}$ (particle size: $38 \mathrm{~nm}$, TEM) [27]. The nickel content was kept constant while the Fe content was varied. The ordered $\mathrm{Ni}_{75} \mathrm{Fe}_{25}$ phase, possibly protected by carbon layers, was identified by XRD for the $\mathrm{Ni}_{67} \mathrm{Fe}_{33} /$ carbon nominal formulation, and by STEM-EDX, though with some variance on chemical composition, for two Fe-richer catalysts, and was associated to a full conversion. Monometallic $\mathrm{Ni}$ rather favored several secondary reactions of coupling: Esterification between stearic acid and stearic alcohol, formation of stearone by ketonization and decarboxylation of two molecules of stearic acid. Similarly, a $16 \mathrm{wt} \% \mathrm{Ni}_{50} \mathrm{Fe}_{50} / \mathrm{SiO}_{2}$ catalyst prepared by co-impregnation and reduced at $450{ }^{\circ} \mathrm{C}$ (average alloy particle size: $5 \mathrm{~nm}$, TEM) provided a 50\% selectivity to dodecanol in the hydroconversion of methyl laurate at $300{ }^{\circ} \mathrm{C}$ in the gas phase, while in the same conditions, an $8 \mathrm{wt} \% \mathrm{Ni} / \mathrm{SiO}_{2}$ catalyst mostly yielded hydrogenolysis products [46].

The optimized hydrogenation of ethyl levulinate (conversion: $100 \%$, selectivity to $\gamma$-valerolactone (GVL): $99 \%$ ) was achieved at $100{ }^{\circ} \mathrm{C}$ in water on a $10 \mathrm{wt} \% \mathrm{Ni}_{67} \mathrm{Fe}_{33}$ catalyst prepared by co-precipitation on activated carbon and reduced at $400{ }^{\circ} \mathrm{C}$ (alloy particle size: $6-10 \mathrm{~nm}$, average size $7.1 \mathrm{~nm}, \mathrm{XRD}$, TEM) [42]. The hydrogenation of the ketone function to a secondary alcohol function was followed by an intramolecular transesterification reaction, with release of an ethanol molecule (Figure 8). With the increase of Fe content at constant Ni content, the conversion and yield increased and reached a maximum for $\mathrm{Ni}_{67} \mathrm{Fe}_{33}$. A further increase led to a decrease of conversion and yield. A $7 \mathrm{wt} \%$ $\mathrm{Ni} /$ carbon catalyst provided a $51.7 \%$ yield of $\gamma$-valerolactone at a conversion of $53.5 \%$; the nature of the side-products was not given. A stability test was carried out, aided by the easy magnetic separation of the $\mathrm{Ni}_{67} \mathrm{Fe}_{33} /$ carbon catalyst. Conversion and selectivity to GVL decreased along the four successive runs. A limited recovery was obtained by regeneration by calcination, and a loss of $3.46 \%$ of $\mathrm{Ni}$ and $6.78 \%$ of Fe was detected. The lack of stability of the catalyst was thus attributed both to the deposition of carbonaceous species and to the leaching of metals in water. 

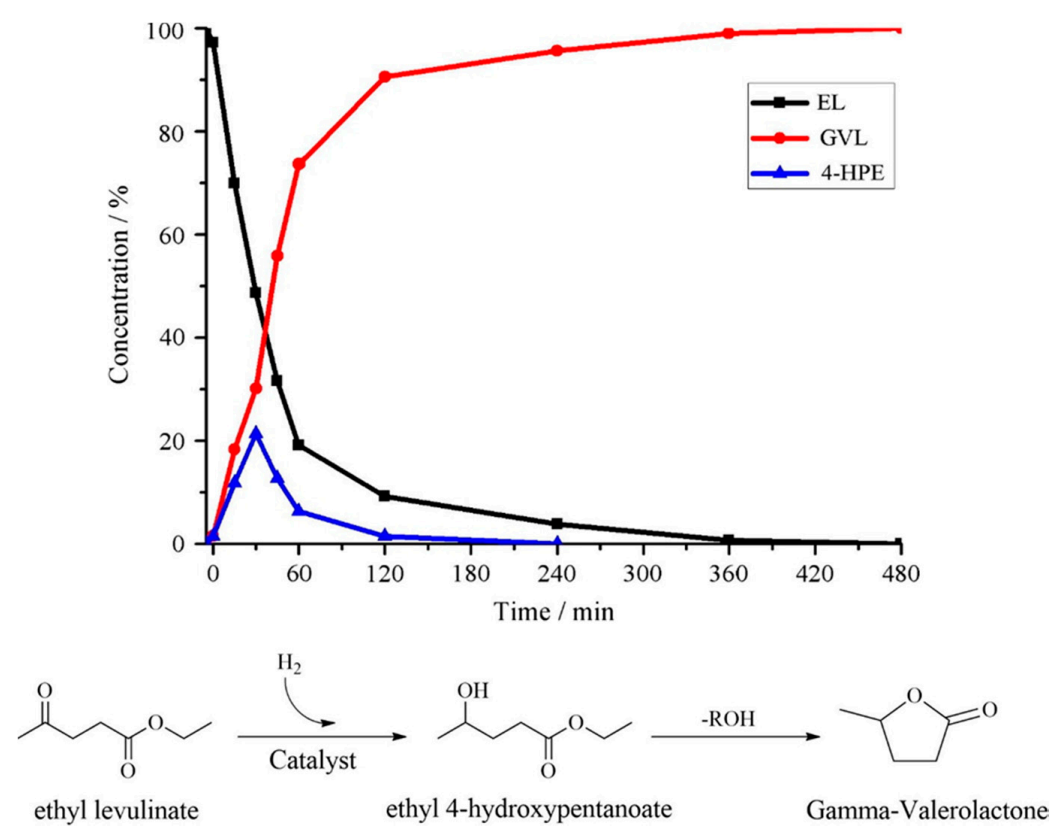

Figure 8. Influence of reaction time on the conversion of ethyl levulinate (EL) to ethyl 4-hydroxypentanoate (4-HPE) and $\gamma$-valerolactone (GVL), using a $10 \mathrm{wt} \% \mathrm{Ni}_{67} \mathrm{Fe}_{33}$ /carbon catalyst reduced at $400{ }^{\circ} \mathrm{C}\left(\mathrm{T}=100^{\circ} \mathrm{C}, \mathrm{P}\left(\mathrm{H}_{2}\right)=40\right.$ bar, solvent: Water $)$. Reprinted from Reference [42], copyright 2017, with permission from Elsevier.

\subsection{Selective Hydrogenation of Nitriles}

The hydrogenation of the $\mathrm{C} \equiv \mathrm{N}$ bond in nitriles, such as benzonitrile, butyronitrile, cinnamonitrile and crotononitrile, was performed at $150{ }^{\circ} \mathrm{C}$ in methanol [17,51]. The $20 \mathrm{wt} \% \mathrm{Ni}_{75} \mathrm{Fe}_{25} / \mathrm{SiO}_{2}$ catalyst presented in Section 3.2 for the hydrogenation of acetophenone was found to represent the optimum formulation (Figure $7 \mathrm{~b}$ ). The articles mention that primary amines were mainly formed along with some secondary amines, and that only saturated nitriles and amines were obtained, but the products were not named. In contrast, it is the secondary amine, N,N-dibenzylamine, that Chieffi et al. reported to be the main product of hydrogenation of benzonitrile at $150{ }^{\circ} \mathrm{C}$ in ethanol, using the $56 \mathrm{wt} \%$ $\mathrm{Ni}_{58} \mathrm{Fe}_{42} /$ carbon catalyst formerly seen in the sections above (conversion: $>99 \%$, selectivity: $40 \%$ ) [34].

\subsection{Selective Hydrogenation of Nitroaromatics}

The selective hydrogenation of nitroaromatics to the corresponding aromatic amines has been reported in three occurrences. Chieffi et al. have carried out the quantitative hydrogenation of nitrobenzene to aniline at $100{ }^{\circ} \mathrm{C}$ in ethanol with $56 \mathrm{wt} \% \mathrm{Ni}_{58} \mathrm{Fe}_{42} /$ carbon (see Section 3.1) [34].

$\mathrm{Ni}-\mathrm{Fe} / \mathrm{N}$-containing carbon catalysts (38-60 wt\%) (constant Fe content, Ni content varying between $\mathrm{Ni} / \mathrm{Fe}$ ratios $=2$ to 4 ) were prepared by co-precipitation, contact with melamine and carbothermal reduction under $\mathrm{N}_{2}$ at $600{ }^{\circ} \mathrm{C}$ [40]. The particle size determined by XRD and TEM was in the 18-26 nm range, and the homogeneity of the particle composition was verified by STEM-EDX. A quantitative reduction of ortho-chloronitrobenzene to ortho-chloroaniline was achieved at $80^{\circ} \mathrm{C}$ in ethanol for a $\mathrm{Ni}_{75} \mathrm{Fe}_{25}$ formulation. It must be noted though that the catalyst mass was kept constant for the kinetic measurements involving the different catalysts, and that the $\mathrm{Ni}_{75} \mathrm{Fe}_{25} / \mathrm{N}$-containing carbon catalyst was the one possessing the highest loading of metals. The other formulations were less active, but almost as selective as $\mathrm{Ni}_{75} \mathrm{Fe}_{25}$, including the analogue monometallic Ni catalyst. Reported conversion and selectivities for other nitroaromatics were similarly elevated.

$\mathrm{Ni}-\mathrm{Fe}$ nanoalloys prepared by carbothermal reduction in $\mathrm{N}_{2}$ at $800^{\circ} \mathrm{C}$ on coal have finally been tested in the hydrogenation of para-nitrophenol by $\mathrm{NaBH}_{4}$ in water [52]. A $6.5 \mathrm{wt} \% \mathrm{Ni}_{45} \mathrm{Fe}_{55} /$ carbon catalyst appeared as 5.4 times more active than the monometallic $\mathrm{Ni}$ analogue system. Interpretation is however difficult as both $\mathrm{Ni}$ and Fe nanoparticles were detected by XRD on the bimetallic catalyst. 


\subsection{Hydroconversion at Higher Temperatures: The Case of Aromatic Rings}

At high temperatures $\left(300-400{ }^{\circ} \mathrm{C}\right)$ and in the gas phase, hydrogenolysis reactions start to predominate. Unlike $\mathrm{Ni}$ catalysts, $\mathrm{Ni}-\mathrm{Fe}$ systems have been shown to prevent the concomitant hydrogenation of aromatic rings. A first hint was given by Guerrero-Ruiz et al. as early as 1992. They showed that the activation energy of a $10 \mathrm{wt} \% \mathrm{Ni}_{39} \mathrm{Fe}_{61} /$ carbon catalyst was $69 \mathrm{~kJ} \mathrm{~mol}^{-1}$ for benzene hydrogenation, compared with $55 \mathrm{~kJ} \mathrm{~mol}^{-1}$ for $5 \mathrm{wt} \% \mathrm{Ni} / \mathrm{carbon}[30,31]$. The Ni-Fe catalysts were prepared by successive impregnations, which after reduction at $400{ }^{\circ} \mathrm{C}$ led to the co-existence of Fe and alloyed particles $\left(2-6 \mathrm{~nm}\right.$ ) as evidenced by ${ }^{57} \mathrm{Fe}$ Mössbauer spectroscopy and TEM. As a Fe/carbon catalyst proved totally inactive in benzene hydrogenation, the increase of activation energy was assigned to the bimetallic nanoparticles.

Leng et al. showed that $20 \mathrm{wt} \% \mathrm{Ni}_{75} \mathrm{Fe}_{25} / \mathrm{Al}_{2} \mathrm{O}_{3}$ catalysts prepared by co-impregnation and reduced at $400{ }^{\circ} \mathrm{C}$ (average particle size: $4.8 \mathrm{~nm}$, TEM) provided an almost quantitative hydrodeoxygenation (HDO) of furfuryl alcohol, benzyl alcohol and ethyl oenanthate to, respectively, 2-methylfuran, toluene and heptane, at atmospheric pressure and at $\mathrm{T}=400{ }^{\circ} \mathrm{C}$ [53]. Fang et al. studied the HDO of guaiacol at $300{ }^{\circ} \mathrm{C}$ over Ni-Fe catalysts supported on carbon nanotubes (CNT), prepared by co-impregnation and reduced at $400{ }^{\circ} \mathrm{C}$ (particle size: 5-8 nm, XRD, TEM, alloying evidenced by XRD and STEM-EDX) [54]. Monometallic $7 \mathrm{wt} \% \mathrm{Ni} / \mathrm{CNT}$ exhibited a $79 \%$ conversion and $60 \%$ selectivity to cyclohexane, the product of full HDO and hydrogenation (Figure 9). An $83.4 \%$ selectivity to cyclohexane at $96.8 \%$ of conversion was obtained with $7 \mathrm{wt} \% \mathrm{Ni}_{83} \mathrm{Fe}_{17} / \mathrm{CNT}$. But when increasing the Fe content, the hydrogenation of the aromatic ring was toned down, as conversion decreased and selectivity was shifted to the production of phenol, such as with $7 \mathrm{wt} \% \mathrm{Ni}_{17} \mathrm{Fe}_{83} / \mathrm{CNT}$ (conversion of guaiacol: $50 \%$, selectivity to phenol: $77 \%$ ). The Ni-Fe nanoparticle size and the reduction temperature were also investigated. Increasing the reduction temperature from 400 to $600{ }^{\circ} \mathrm{C}$ increased the size of $\mathrm{Ni}_{83} \mathrm{Fe}_{17}$ nanoparticles from 7.7 to $11.2 \mathrm{~nm}$, leading to a decrease of the selectivity to cyclohexane from $85.4 \%$ to $55.8 \%$, and an increase of the selectivity to cyclohexanol from $12.7 \%$ to $31.9 \%$ at full conversion. No phenol was produced. This indicates that the preservation of the aromatic ring is heavily linked to the Fe content of the nanoparticles.
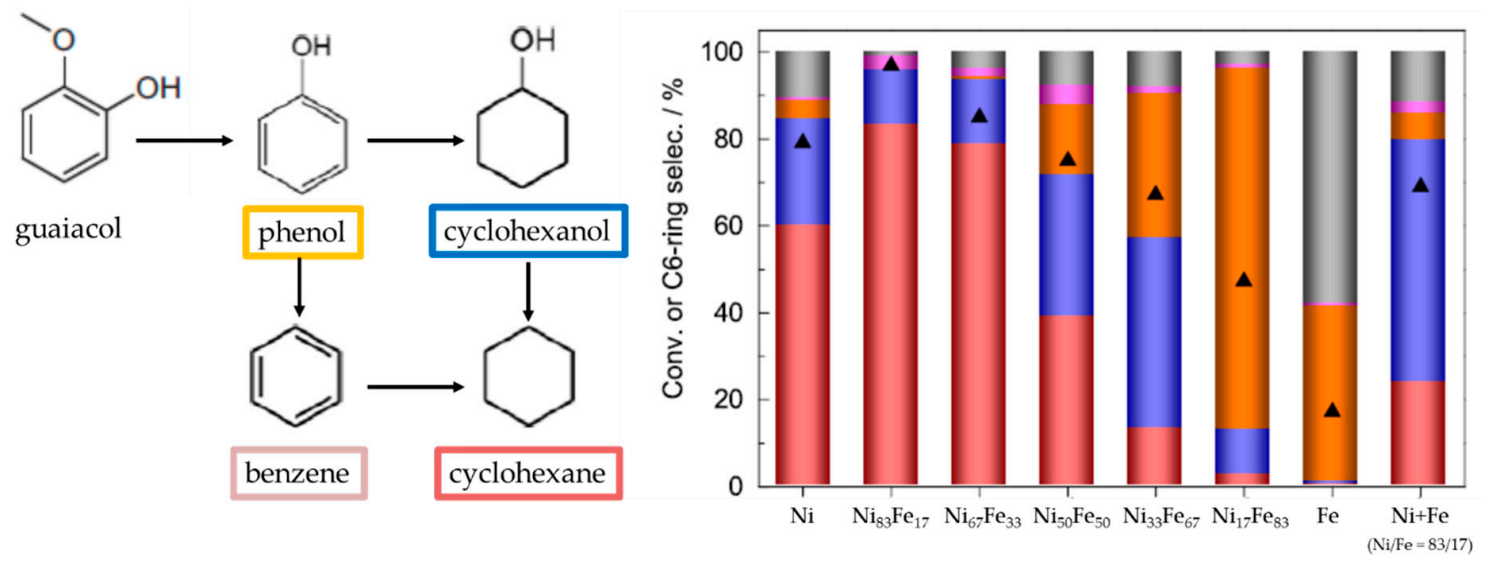

Figure 9. Catalytic performances of $\mathrm{Ni}-\mathrm{Fe} /$ carbon nanotube catalysts in the hydrodeoxygenation of guaiacol in the gas phase, as a function of the $\mathrm{Ni}$ and Fe molar proportions $\left(\mathrm{T}=300{ }^{\circ} \mathrm{C}, \mathrm{P}\left(\mathrm{H}_{2}\right)=30\right.$ bar). Conversion: Triangles, selectivities: Bars. Adapted from Reference [32], copyright 2017, with permission from Elsevier.

The effect of Fe has also been surveyed by Nie et al. for the $\mathrm{HDO}$ of meta-cresol at $300{ }^{\circ} \mathrm{C}$, and similar tendencies were found [22]. The predominant product for a $15 \mathrm{wt} \% \mathrm{Ni} / \mathrm{SiO}_{2}$ catalyst was the product of hydrogenation and tautomerization, 3-methylcyclohexanone (conversion: $16.2 \%$, selectivity: $33.3 \%$ ). Instead, for a $15 \mathrm{wt} \% \mathrm{Ni}_{50} \mathrm{Fe}_{50} / \mathrm{SiO}_{2}$ catalyst prepared by co-impregnation and reduced at $450{ }^{\circ} \mathrm{C}$ (average particle size: $10 \mathrm{~nm}, \mathrm{XRD}$ ), the predominant product at a conversion of $13.7 \%$ was 
toluene (selectivity: $52.6 \%$ ). Toluene was the only product detected with a $\mathrm{Ni}_{33} \mathrm{Fe}_{67} / \mathrm{SiO}_{2}$ catalyst that contained both alloyed and Fe-rich nanoparticles (XRD). Density functional theory (DFT) studies and microkinetic modelling suggest that the aromatic ring is preserved from hydrogenation on $\mathrm{Ni}-\mathrm{Fe}$ catalysts, which ensure the direct hydrogenolysis of the $\mathrm{C}-\mathrm{O}$ bond, whereas Ni would rather transform the unsaturated ketone tautomer of meta-cresol [54]. A more complex route to toluene, involving the dehydration of the unsaturated alcohol resulting from the selective hydrogenation of the ketone tautomer, had been formerly postulated to explain the selectivity of the Ni-Fe catalysts [22].

\subsection{Hydrogenation of Furanic Compounds}

Given their specific reactivity and the multiplicity of transformations to which this family of molecules can be subjected, results obtained in the hydroconversion of furfural and 5-hydroxymethyl furfural will be presented separately in this section.

Furfural holds an aromatic furan ring, which can undergo hydrogenation and ring-opening reactions, and a side-group containing an aldehyde function $-\mathrm{CH}=\mathrm{O}$, which can be hydrogenated, hydrogenolyzed, or removed by decarbonylation (Figure 10) [55]. The selective hydrogenation of the aldehyde group of furfural leads to furfuryl alcohol (noted by FOL below), an intermediate in the production of fine chemicals and synthetic fibers. Tetrahydrofurfuryl alcohol (THFOL), a key intermediate for the synthesis of vitamin C, plasticizers, lubricants and lysine, is produced by hydrogenation of the furan ring of FOL. The hydrogenolysis of the $\mathrm{C}-\mathrm{O}$ bond of the alcohols yields fuel additives, 2-methyl-furan (MF), from FOL, or 2-methyltetrahydrofuran (MTHF), from THFOL (the hydrogenation of the ring of MF being another possible route to MTHF). In a competing route, decarbonylation of furfural leads to furan, which can be hydrogenated into tetrahydrofuran (THF).

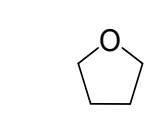

tetrahydrofuran

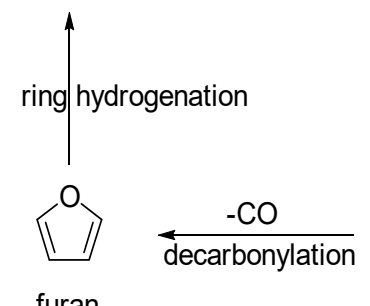

furan furfura

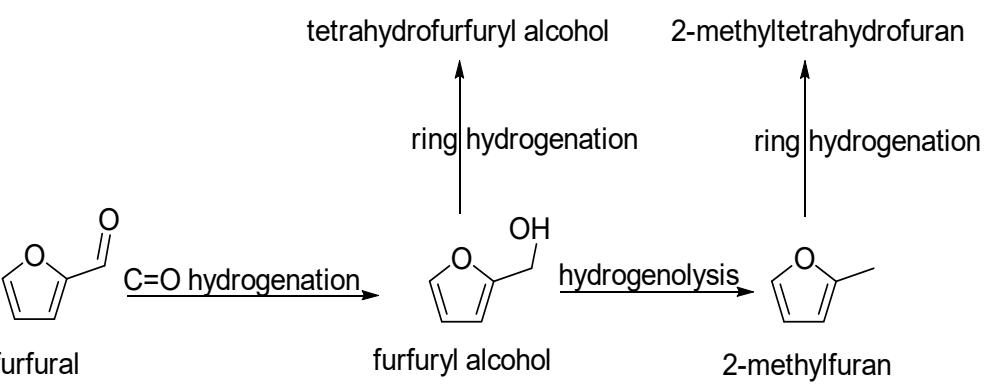

Figure 10. Main transformations of furfural in hydroconversion conditions. Adapted from Reference [55].

$\mathrm{Ni}-\mathrm{Fe}$ bimetallic catalysts prepared by co-impregnation and reduced at $450{ }^{\circ} \mathrm{C}$ (average particle size: $10 \mathrm{~nm}$, XRD; $16-17 \mathrm{~nm}$, TEM) have been explored by Sitthisa et al. for the hydroconversion of furfural in the gas phase between 210 and $250^{\circ} \mathrm{C}$ (Figure 11) [21]. Furan, the decarbonylation product, was the main product of hydroconversion over a $5 \mathrm{wt} \% \mathrm{Ni} / \mathrm{SiO}_{2}$ catalyst at $250{ }^{\circ} \mathrm{C}$ (conversion of furfural: $98 \%$, yield of furan: $50 \%$ ). On Ni-Fe bimetallic catalysts, a high conversion was also obtained (96.3\% for $7 \mathrm{wt} \% \mathrm{Ni}_{71} \mathrm{Fe}_{29} / \mathrm{SiO}_{2}$ ), but the yield of 2-methylfuran greatly increased (from $5 \%$ at $250{ }^{\circ} \mathrm{C}$ for $7 \mathrm{wt} \% \mathrm{Ni} / \mathrm{SiO}_{2}$, to $39.1 \%$ for $7 \mathrm{wt} \% \mathrm{Ni}_{71} \mathrm{Fe}_{29} / \mathrm{SiO}_{2}$ ) while the yields of furan decreased (from $50 \%$ for $7 \mathrm{wt} \% \mathrm{Ni} / \mathrm{SiO}_{2}$, to $12.1 \%$ for $7 \mathrm{wt} \% \mathrm{Ni}_{71} \mathrm{Fe}_{29} / \mathrm{SiO}_{2}$ ). The yield of $\mathrm{FOL}$ was comprised between $22 \%$ and $32 \%$ at $210^{\circ} \mathrm{C}$ both for the $\mathrm{Ni}$ and $\mathrm{Ni}-\mathrm{Fe}$ catalysts, but became low at $250{ }^{\circ} \mathrm{C}$. At that temperature, $7 \mathrm{wt} \%$ $\mathrm{Ni} / \mathrm{SiO}_{2}$ did not yield any FOL, while a yield of $10 \%$ was obtained for $7 \mathrm{wt} \% \mathrm{Ni}_{71} / \mathrm{Fe}_{29} \mathrm{SiO}_{2}$. It decreased when further increasing the Fe content (conversion of furfural for $7 \mathrm{wt} \% \mathrm{Ni}_{50} \mathrm{Fe}_{50} / \mathrm{SiO}_{2}<30 \%$, yield of FOL: $6 \%$ ). $\mathrm{C}_{4}$ and $\mathrm{C}_{5}$ ring-opening products were detected in large amounts for the $\mathrm{Ni}$ and the $\mathrm{Ni}-\mathrm{Fe}$ catalysts in these experimental conditions. In summary, the addition of Fe suppressed the decarbonylation properties of $\mathrm{Ni}$, while promoting both $\mathrm{C}=\mathrm{O}$ hydrogenation and $\mathrm{C}-\mathrm{O}$ hydrogenolysis 
reactions. Complementary experiments carried out with FOL and benzyl alcohol confirmed that $\mathrm{Ni}-\mathrm{Fe}$ catalysts are more selective catalysts than $\mathrm{Ni}$ for the hydrogenolysis of the $\mathrm{C}-\mathrm{O}$ bond of alcohols. These trends have been recently confirmed by Wang et al. (10 $\mathrm{wt} \% \mathrm{Ni}_{50} \mathrm{Fe}_{50} /$ carbon catalysts prepared by co-impregnation and reduced at $500{ }^{\circ} \mathrm{C}$, large distribution of particle sizes, average value: $12 \mathrm{~nm}$, TEM) [56].

(a)

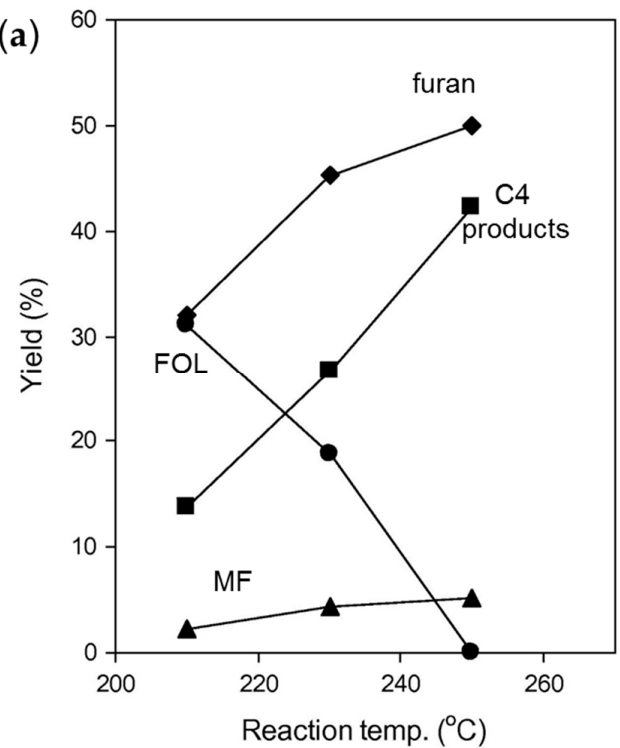

(b)

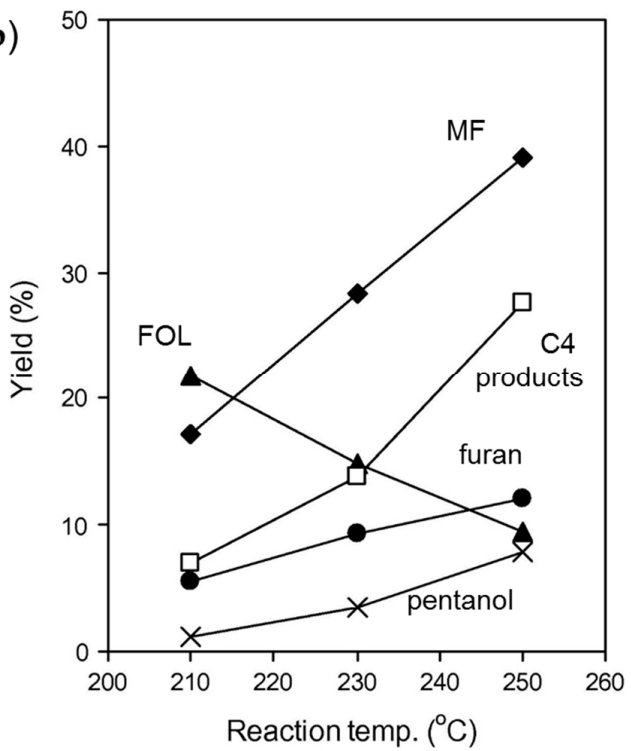

Figure 11. Yields of products obtained by hydroconversion of furfural in the gas phase at atmospheric pressure as a function of temperature, using (a) a $5 \mathrm{wt} \% \mathrm{Ni} / \mathrm{SiO}_{2}$ catalyst; (b) a $7 \mathrm{wt} \% \mathrm{Ni}_{71} \mathrm{Fe}_{29} / \mathrm{SiO}_{2}$ catalyst. Adapted from Reference [21], copyright 2011, with permission from Elsevier.

In the liquid phase (2-propanol) at $150{ }^{\circ} \mathrm{C}$, Putro et al. obtained a $95 \%$ furfural conversion with $97 \%$ selectivity to $\mathrm{FOL}$ using a $20 \mathrm{wt} \% \mathrm{Ni}_{75} \mathrm{Fe}_{25} / \mathrm{Al}_{2} \mathrm{O}_{3}$ catalyst (preparation and characteristics described in Section 3.2) [26]. The higher dispersion of $\mathrm{Ni}_{75} \mathrm{Fe}_{25}$ nanoparticles on $\mathrm{CeO}_{2}, \mathrm{Al}_{2} \mathrm{O}_{3}$ and $\mathrm{TiO}_{2}$ supports enhanced the catalyst intrinsic activity (conversion: $99 \%, 95 \%$ and $100 \%$, respectively) and selectivity (93\%, 97\% and 91\%, respectively), compared to unsupported $\mathrm{Ni}_{75} \mathrm{Fe}_{25}$ and $\mathrm{Ni}$ (respective conversion: $90 \%$ and $100 \%$, and selectivity: $92 \%$ and $7 \%$ ). The main product formed with Ni was THFOL, the product of hydrogenation of the furan ring (selectivity: $61 \%$ ). The values were also much higher than those measured on $\mathrm{SiO}_{2}$, taeniolite or hydrotalcite supports (conversion: $21 \%, 22 \%$ and $42 \%$; selectivities: $95 \%, 77 \%$ and $90 \%$ ) which all increased the selectivity to THFOL ( $5 \%, 23 \%$ and $10 \%)$.

Chieffi et al. also found that in ethanol at $150{ }^{\circ} \mathrm{C}, \mathrm{Ni}_{58} \mathrm{Fe}_{42}$ particles supported on carbon (described in Section 3.1) exhibited a high conversion of furfural (99\%) and selectivity to FOL (90\%) [34]. The same tendency was evidenced by Shi et al. [28]. A $52 \mathrm{wt} \% \mathrm{Ni}_{69} \mathrm{Fe}_{31} / \mathrm{SiO}_{2}$ catalyst prepared by DP with urea and reduced at $700{ }^{\circ} \mathrm{C}$ (particle size: $4-7 \mathrm{~nm}$, TEM) appeared to be more selective to FOL in 2-propanol at $150{ }^{\circ} \mathrm{C}$ (yield $>80 \%$ at full conversion) than the homologue $\mathrm{Ni} / \mathrm{SiO}_{2}$ catalyst that favored the hydrogenation of the furan ring to THFOL at lower furfural concentrations, and the hydrogenolysis to MF, and hydrogenolysis/hydrogenation of the furan ring to MTHF at higher concentrations. Side-reactions of etherification between the furanic alcohols and the solvent were also evidenced. These reactions appeared as prominent with a $\mathrm{Ni}_{69} \mathrm{Fe}_{31} / \mathrm{SiO}_{2}$ catalyst that was incompletely reduced.

Using heptane as a solvent, Halilu et al. showed that at $250{ }^{\circ} \mathrm{C}$, when increasing the Ni content from $0.05 \mathrm{wt} \%$ to $0.5 \mathrm{wt} \%$ in a magnetic $\mathrm{Ni}-\mathrm{Fe}_{3} \mathrm{O}_{4}-\mathrm{SiO}_{2}$ nanocatalyst $\left(\mathrm{Ni}^{2+}\right.$ ions loaded on the surface of a $\mathrm{Fe}_{3} \mathrm{O}_{4}-\mathrm{SiO}_{2}$ core-shell structure, reduced at $500{ }^{\circ} \mathrm{C}$ ), the conversion of furfural increased from $55 \%$ to $94 \%$ while the selectivity to FOL was kept at $\sim 100 \%$ in the whole series [57]. With $0.5 \mathrm{wt} \% \mathrm{Ni} / \mathrm{SiO}_{2}$, the conversion of furfural was only $50 \%$, the selectivity to FOL $25 \%$, and a wide range of products was obtained due to decarbonylation and ring opening reactions, such as furan (selectivity: $48 \%$ ), butanal (selectivity: 13\%), butanol (selectivity: 3\%) and butane (selectivity: $11 \%$ ). 
The selective hydrogenation and hydrogenolysis of a molecule close to furfural, 5-hydroxymethylfurfural, were investigated by Yu et al. using carbon nanotube-supported $\mathrm{Ni}-\mathrm{Fe}$ catalysts ( $\mathrm{Ni}-\mathrm{Fe} / \mathrm{CNT}$ ) prepared by co-impregnation and reduced at $400{ }^{\circ} \mathrm{C}$ (average alloy particle size: $6.5 \mathrm{~nm}$, TEM, STEM-EDX) [58]. Two side-groups are held by 5-hydroxymethylfurfural: An aldehyde function like furfural, and a $-\mathrm{CH}_{2} \mathrm{OH}$ function (Figure 12a). Monometallic $10 \mathrm{wt} \% \mathrm{Ni} / \mathrm{CNT}$ catalyst displayed a high conversion at $110^{\circ} \mathrm{C}$ in butanol $(100 \%)$, but a selectivity to the diol, 2,5 -furandimethanol, of only $76.4 \%$. The byproducts of the reaction included decarbonylation (5-methylfurfural), ring opening (1,2-hexanediol), etherification products (grouped as "others" on Figure 12b), and hydrogenolysis and ring hydrogenation products (5-methyl 2-furanmethanol, 2,5-dimethylfuran, 2,5-dimethyltetrahydrofuran). Even a small addition of Fe to $\mathrm{Ni}$ increased the selectivity to 2,5-furandimethanol ( $87.7 \%$ for $\left.10 \mathrm{wt} \% \mathrm{Ni}_{91} \mathrm{Fe}_{9} / \mathrm{CNT}\right)$ while keeping the conversion at $100 \%$. A selectivity of $97.5 \%$ to 2,5 -furandimethanol at $100 \%$ of conversion could be achieved with $10 \mathrm{wt} \% \mathrm{Ni}_{50} \mathrm{Fe}_{50} / \mathrm{CNT}$. Chieffi et al. also found that in ethanol at $150{ }^{\circ} \mathrm{C}$, $\mathrm{Ni}_{58} \mathrm{Fe}_{42} /$ carbon supplied a high conversion of 5-hydroxymethylfurfural (99\%) and a high selectivity to 2,5-furandimethanol (88\%) [34].

(a)

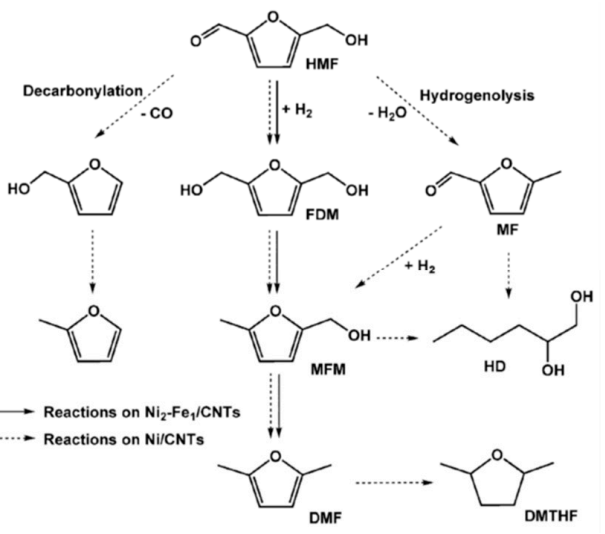

(b)

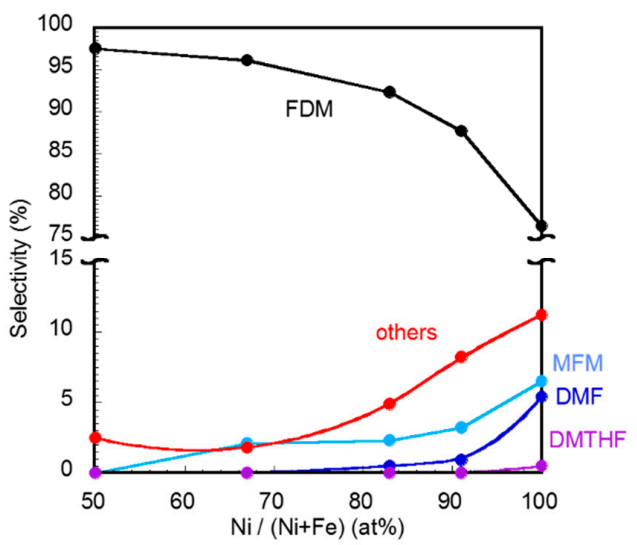

Figure 12. (a) Hydroconversion of 5-hydroxymethylfurfural: Reaction pathways favored by a Ni/carbon nanotubes catalyst and by a $\mathrm{Ni}_{67} \mathrm{Fe}_{33} /$ carbon nanotube catalyst (FDM: 2,5-furandimethanol, MF: 5-methyl furfural, MFM: 5-methyl 2-furanmethanol, DMF: 2,5-dimethylfuran, DMTHF: 2,5-dimethyl tetrahydrofuran, HD: 1,2-hexanediol). Reprinted from Reference [58], copyright 2015, with permission from Wiley; (b) selectivities obtained as a function of the Ni molar proportion $\left(\mathrm{T}=110^{\circ} \mathrm{C}, \mathrm{P}\left(\mathrm{H}_{2}\right)=30 \mathrm{bar}\right.$, solvent: n-butanol; others: Ethers, decarbonylation product, ring-opening products, humin). Based on data from Reference [58].

The products distribution was completely changed to hydrogenolysis products when the reaction temperature was increased to $200{ }^{\circ} \mathrm{C}$. The main product was then 2,5-dimethylfuran (selectivity: $46.3 \%$ ) for monometallic Ni/CNT catalyst at $100 \%$ conversion (selectivity to 2,5-furandimethanol: 13.4\%). After increasing the Fe content up to $\mathrm{Ni}_{67} \mathrm{Fe}_{33} / \mathrm{CNT}$, the selectivity to 2,5-dimethylfuran was $91.3 \%$ at $100 \%$ conversion and no 2,5-furandimethanol was formed. Fe thus appeared to increase the catalyst selectivity associated to the aldehyde and alcohol side-groups, both toward selective hydrogenation products at lower temperature, and to hydrogenolysis products at higher temperature, while preventing reactions involving the furan ring. A stability test over seven runs showed that the full conversion was retained while the selectivity to 2,5-dimethylfuran (DMF) decreased from $90 \%$ to $75 \%$. Deactivation was ascribed to the deposition of carbonaceous molecules, rather than to metal leaching or sintering.

This survey from the literature clearly shows that whatever the support, fcc Ni-Fe phases in the range of formulation $\mathrm{Ni}_{50} \mathrm{Fe}_{50}-\mathrm{Ni}_{80} \mathrm{Fe}_{20}$ often provide the best results in terms of activity and selectivity. The $\mathrm{Ni}_{75} \mathrm{Fe}_{25}$ formulation is also the one that has become favored for $\mathrm{CO}$ and $\mathrm{CO}_{2}$ hydrogenation $[9,10,14,15,41,59,60]$, while the $\mathrm{Ni}_{80} \mathrm{Fe}_{20}$ formulation was found to be the most active for dry and steam reforming $[3,8]$. It must be noted though that comparison between different catalysts, or between different works, should be done with caution for several reasons: 
- The nature of the Ni-Fe nanoparticles on the catalyst is not always homogeneous (mixture of bcc and fcc phases, of particles with different compositions).

- The temperature of reduction is usually lower than $500^{\circ} \mathrm{C}$ : There is a, sometimes demonstrated, risk that $\mathrm{Fe}$, and even $\mathrm{Ni}$, reduction is not complete after activation in $\mathrm{H}_{2}$ (X-ray photoelectron spectroscopy (XPS) measurements [32,42]; FTIR measurements [22]).

- $\mathrm{SiO}_{2}$, and various types of carbon, have been used as supports in most of the articles, but specific effects involving supports such as $\mathrm{Al}_{2} \mathrm{O}_{3}$ and $\mathrm{TiO}_{2}$ have been reported.

- Even for a given support and for a similar procedure of preparation (co-impregnation or precipitation), discrepancies are large between the different articles in terms of particle size. Some size-dependent effects on catalytic performances have however been reported [26,32].

- Selectivities and yields may be given only at high or full conversion, which does not allow a clear comparison between different systems, and makes discussion difficult. A kinetic study carried out as a function of reaction time, or at increasing conversion, is often lacking.

- A limited number of $\mathrm{Ni}-\mathrm{Fe}$ formulations is usually tested.

- In some cases, the metals loading varies along with the nanoparticle formulation (when the content in one of the metals is kept constant while the other one increases), while the mass of catalyst used for catalytic test remains the same, possibly skewing comparisons of activities.

Nevertheless, several tendencies emerge when Ni-Fe catalysts are compared with Ni catalysts:

- The hydrogenation of $\mathrm{C}=\mathrm{C}, \mathrm{C}=\mathrm{O}$ and $\mathrm{C} \equiv \mathrm{N}$ bonds has been reported to be faster for the bimetallic formulations.

- Ni-Fe catalysts are more selective than Ni for the hydrogenation of $\mathrm{C} \equiv \mathrm{C}$ and $\mathrm{C}=\mathrm{O}$ bonds, to alkenes vs. alkanes, and to alcohols vs. secondary products, respectively. In particular, the hydrogenation of aromatic rings, and the opening of furanic rings, are often toned down on $\mathrm{Ni}-\mathrm{Fe}$ systems. At higher temperatures, the hydrogenolysis of $\mathrm{C}-\mathrm{O}$ bonds is avoided on optimal formulations.

- The result of the hydrogenation of a molecule that contains both a $\mathrm{C}=\mathrm{C}$ and a $\mathrm{C}=\mathrm{O}$ bond depends on the relative localization of the two bonds. A distance of several bonds between the two functions seems to result in the preferential hydrogenation of the $\mathrm{C}=\mathrm{O}$ bond, while the outcome is less clear-cut for $\alpha, \beta$-unsaturated carbonyls.

\section{The Role of the Two Metals in the Reactivity of Ni-Fe Nanoparticles: Hypotheses and Open Questions}

To account for the specificities of Ni-Fe catalysts, four categories of explanations have been proposed so far. They are respectively based on the structure of Ni-Fe particles; on their global electronic properties; on the interaction between adsorbates and the surface of the Ni-Fe nanoparticles; finally, on the existence of an excess of Fe atoms at the surface of the nanoparticles.

\subsection{Structural and Geometric Effects}

Matsuyama et al. have first proposed that fcc Ni-Fe phases are more active than bcc phases in the hydrogenation of ethylene because of a higher solubility of hydrogen in their core [20]. However, crystal structure and chemical composition of the alloys are correlated parameters, and it is not possible to consider them separately.

Kojima et al. have interpreted the reactivity of propyne on $\mathrm{Ni}-\mathrm{Fe}$ surfaces as the result of a simple balance between $\mathrm{Ni}$ domains and $\mathrm{Ni}-\mathrm{Fe}$ ensembles, directly derived from the molar composition of the bulk alloy [49]. Fewer Ni domains would lead to less available hydrogen and to a catalyst that limits the hydrogenation of the alkyne to the alkene. Kumbahr et al. and Yadav et al. also recognized the higher activity of fcc phases in the hydrogenation of acetophenone and benzonitrile. They would present the right balance between $\mathrm{Ni}$ domains active in the chemisorption of $\mathrm{H}_{2}$, and Ni-Fe ensembles presumably involved in the activation of the organic substrate $[17,51]$. 


\subsection{Electronic Effects}

Several teams have gone beyond mere geometric effects, and have attributed the performances of Ni-Fe systems to global electronic properties. Ray et al. have associated the activity of $\mathrm{Ni}_{75} \mathrm{Fe}_{25}$ surfaces in $\mathrm{CO}_{2}$ methanation to a minimal number of $\mathrm{Ni} \mathrm{d}$ density of states at the Fermi level [61,62]. In contrast, $\mathrm{Yu}$ and Chen have demonstrated that covering $\mathrm{Ni}$ with a monolayer of Fe atoms would lead to an increased density of states at the Fermi level, that would explain the stronger binding energy of adsorbates on $\mathrm{Fe} / \mathrm{Ni}(111)$ compared with $\mathrm{Ni}(111)$ [63].

Actually, the adsorption of $\mathrm{NO}$ on Ni-Fe nanoparticles followed by infrared spectroscopy revealed a high proportion of bent-type " $\mathrm{NO}^{-1}$ species $\left(1820-1827 \mathrm{~cm}^{-1}\right)$, with respect to linear-type " $\mathrm{NO}^{+ \text {" }}$ species (1874-1878 $\left.\mathrm{cm}^{-1}\right)$, characteristic of an increase of electron donation toward the anti-bonding orbitals of the adsorbates, with a maximum found for the $\mathrm{Ni}_{50} \mathrm{Fe}_{50}$ composition [64]. It should be noted though that the linear type, and the bent type, could not be observed on monometallic catalysts containing $\mathrm{Fe}$, and $\mathrm{Ni}$, respectively, and that this interpretation does not necessarily reveal synergistic effects between the two metals.

The existence of a stronger back-donation toward the anti-bonding orbitals of the adsorbate is in line with the findings from Andersson et al., who correlated the superior activity of $\mathrm{Ni}_{75} \mathrm{Fe}_{25}$ and $\mathrm{Ni}_{50} \mathrm{Fe}_{50}$ alloy surfaces in the hydrogenation of $\mathrm{CO}$ to the dissociation energy of $\mathrm{CO}\left(\mathrm{E}_{\text {diss }}\right)$ used as a relevant descriptor (Figure 13A) [9]. Compared with the optimal value of $\mathrm{E}_{\text {diss optimal }}=0.06 \mathrm{eV}$ determined by DFT for Co and $\mathrm{Ru}$, the calculated gap $\Delta \mathrm{E}_{\text {diss }}=\mathrm{E}_{\text {diss }}-\mathrm{E}_{\text {diss optimal }}$ for $\mathrm{Ni}_{75} \mathrm{Fe}_{25}$ and $\mathrm{Ni}_{50} \mathrm{Fe}_{50}$ was calculated to be lower than $0.25 \mathrm{eV}$, while it was significantly higher for $\mathrm{Fe}(0.9 \mathrm{eV})$ and $\mathrm{Ni}(0.4 \mathrm{eV})$. The relevance of this descriptor for $\mathrm{CO}$ hydrogenation was experimentally confirmed by Hwang et al. using temperature-programmed surface reactions [12,13]. Experimental measurements in the hydrogenation of $\mathrm{CO}$ confirm the superior performances of the Ni-rich alloyed phases for different supports and metal loadings (Figure 13B,C) [10]. We should note though that these correlations remain global, and are not based on the formation and reactivity of intermediates, or on kinetic parameters.

(A)

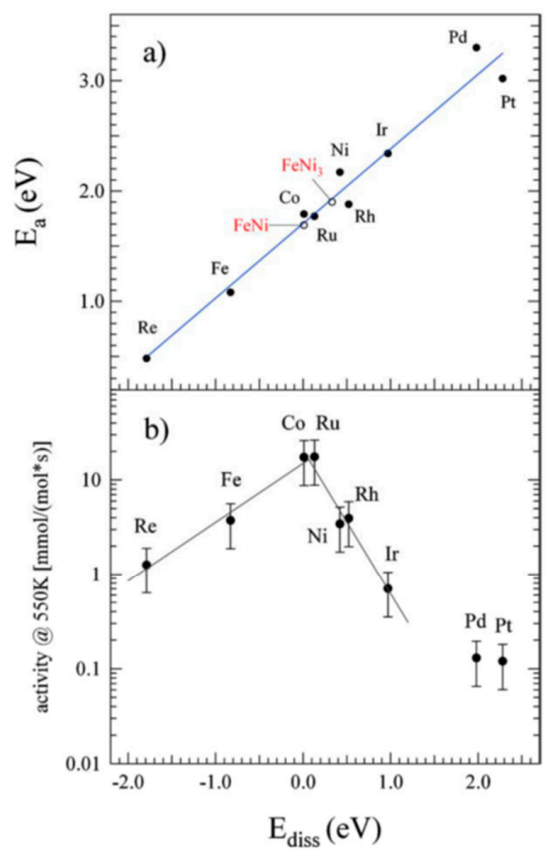

(B)

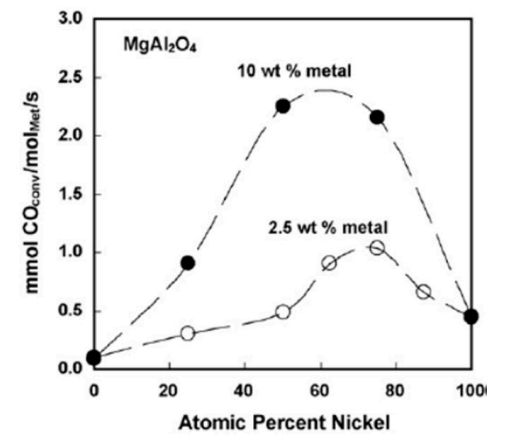

(C)

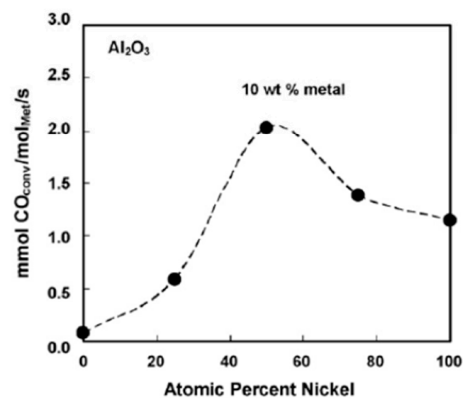

Figure 13. Right: (A) Correlation between (a) the activation energy in CO hydrogenation ( $\left.E_{a}\right)$, (b) the measured activity in CO hydrogenation, and the dissociation energy of CO evaluated by DFT $\left(\mathrm{E}_{\text {diss }}\right)$, evidencing the close properties of the $\mathrm{Ni}_{50} \mathrm{Fe}_{50}$ and $\mathrm{Ni}_{75} \mathrm{Fe}_{25}$ surfaces with respect to Co and $\mathrm{Ru}$. Reprinted from Reference [9], copyright 2006, with permission from Elsevier; Left: Measured reaction rates in the hydrogenation of $\mathrm{CO}$ at $225^{\circ} \mathrm{C}$ for $(\mathrm{B}) \mathrm{Ni}-\mathrm{Fe} / \mathrm{MgAl}_{2} \mathrm{O}_{4}$ and $(\mathrm{C}) \mathrm{Ni}-\mathrm{Fe} / \mathrm{Al}_{2} \mathrm{O}_{3}$ catalysts. Reprinted from Reference [10], copyright 2007, with permission from Elsevier. 


\subsection{Specificity of the Interactions between Ni-Fe Surfaces and Adsorbates}

The explanations presented above omit the description of surface active sites, and do not provide a precise definition of the role of the two metals in the adsorption of the substrate to hydrogenate. In this respect, several interpretations concur in showing that $\mathrm{Ni}$ and Fe actually play different and complementary roles on the alloyed surfaces.

Fe is a more electropositive metal compared to Ni. It was supposed by Yadav and Kharkara that a charge transfer from $\mathrm{Fe}$ to $\mathrm{Ni}$ took place on $\mathrm{Ni}_{75} \mathrm{Fe}_{25}$ particles, with an increase of electron density on $\mathrm{Ni}$ that should lead to strengthened metal-carbon bonding, and weakening of adsorbed polar functions (ketone, nitrile) [51].

$\mathrm{Fe}$ also displays a stronger affinity to oxygen than Ni. The oxophilicity of Fe with respect to $\mathrm{Ni}$ has in fact been listed as a key factor for the performances of Ni-Fe catalysts in the reforming of organic molecules and $\mathrm{CO}_{2}$ hydrogenation. $\mathrm{Li}$ et al. have stated that in reforming reactions, $\mathrm{Ni}$ atoms act as adsorption sites for the organic molecules, while Fe activates water [4]. Kim et al. have shown by operando characterization that under dry reforming conditions, small de-mixed domains of $\mathrm{FeO}$ reversibly form at the surface of the nanoparticles, and enable carbon oxidation and removal [8]. Pandey et al. have considered that oxidized Fe may be beneficial to the hydrogenation of $\mathrm{CO}_{2}$, as it facilitates its adsorption [14,15].

These two properties of Fe can be brought together to explain the specific adsorption mode of polar functions on Ni-Fe surfaces. In the hydrogenation of furfural in the gas phase, the effect of Fe was attributed by Sitthisa et al. to the increase of the stability of $\eta^{2}(C, O)$ surface intermediates, in which the $\mathrm{O}$ atom of the aldehyde function interacts with oxophilic Fe atoms [21]. Compared with $\mathrm{Ni}$, a longer $\mathrm{C}-\mathrm{O}$ bond was found on a $\mathrm{Ni}_{50} \mathrm{Fe}_{50}$ surface, indicating a favored electron back-donation from the metals to the anti-bonding $\pi^{*}$ orbital of the carbonyl function. In contrast, monometallic $\mathrm{Ni}$ interacts primarily with the carbon atom from the aldehyde function, preparing the cleavage of the $\mathrm{C}-\mathrm{C}$ bond between the furan ring and the side group, and the decarbonylation of furfural to furan.

These observations were corroborated by Yu et al., who used DFT calculations and surface science studies on $\mathrm{Fe} / \mathrm{Ni}(111)$, alloyed $\mathrm{Ni}-\mathrm{Fe}$ and $\mathrm{Ni}(111)$ surfaces to determine the most favorable reaction pathways involving furfural [65]. Furfural was found to bond onto Fe-rich surfaces more strongly through the carbonyl group than onto Ni surfaces, with a longer $\mathrm{C}-\mathrm{O}$ bond in the adsorbed molecule and a shorter $\mathrm{O}-\mathrm{M}$ bond. The furan ring was tilted away from the Ni-Fe surface, preventing its hydrogenation. The same repulsive effect may not be effective for $\alpha, \beta$-unsaturated carbonyls, as the proximity between the $\mathrm{C}=\mathrm{C}$ and the $\mathrm{C}=\mathrm{O}$ bonds tends to favor the hydrogenation of the two bonds, or of the $\mathrm{C}=\mathrm{C}$ bond [26].

A dual role assigned on the one hand to Fe for the optimal adsorption of carboxylic groups and ester functions, and on the other hand to $\mathrm{Ni}$ for the adsorption of $\mathrm{H}_{2}$, was postulated by Kong et al. to account for the performances of the $\mathrm{Ni}_{75} \mathrm{Fe}_{25}$ phase in the hydrogenation of stearic acid [27], and by $\mathrm{Yu}$ et al. for the hydroconversion of methyl laurate [46]. Using propanoic acid as a model reactant (Figure 14), Kong et al. have demonstrated that the kinetically-favored pathway is the adsorption and activation of the acid via the carboxylic group on a Ni-Fe pair, followed by its deoxygenation to a $\mathrm{CH}_{3}-\mathrm{CH}_{2}-\mathrm{CO}^{*}$ intermediate which finally undergoes hydrogenation to propanol.

Besides, the reaction order with respect to $\mathrm{H}_{2}$ in the hydrogenation of stearic acid was measured to increase from 0.6 on a Ni catalyst to 1.6 on the bimetallic phase, indicating that Ni ensembles on $\mathrm{Ni}-\mathrm{Fe}$ nanoparticles present specificities with respect to $\mathrm{H}_{2}$ activation. Fang et al. have supposed that the adsorption of guaiacol takes place preferentially at the surface of oxophilic Fe domains, and that $\mathrm{Ni}$ would be required for the dissociation of $\mathrm{H}_{2}$; the production of phenol on Fe-rich surfaces was linked to an insufficient amount of available activated hydrogen atoms to allow the hydrogenation of the aromatic ring [32].

While confirming the role of Fe in the adsorption of oxygenates on Ni-Fe catalyst, Li et al. have rather emphasized the action of oxidized Fe species, through their Lewis acidity, instead of metallic Fe atoms [42]. This point should not be neglected, as Fe may appear as ionic species if its reduction is not complete. 

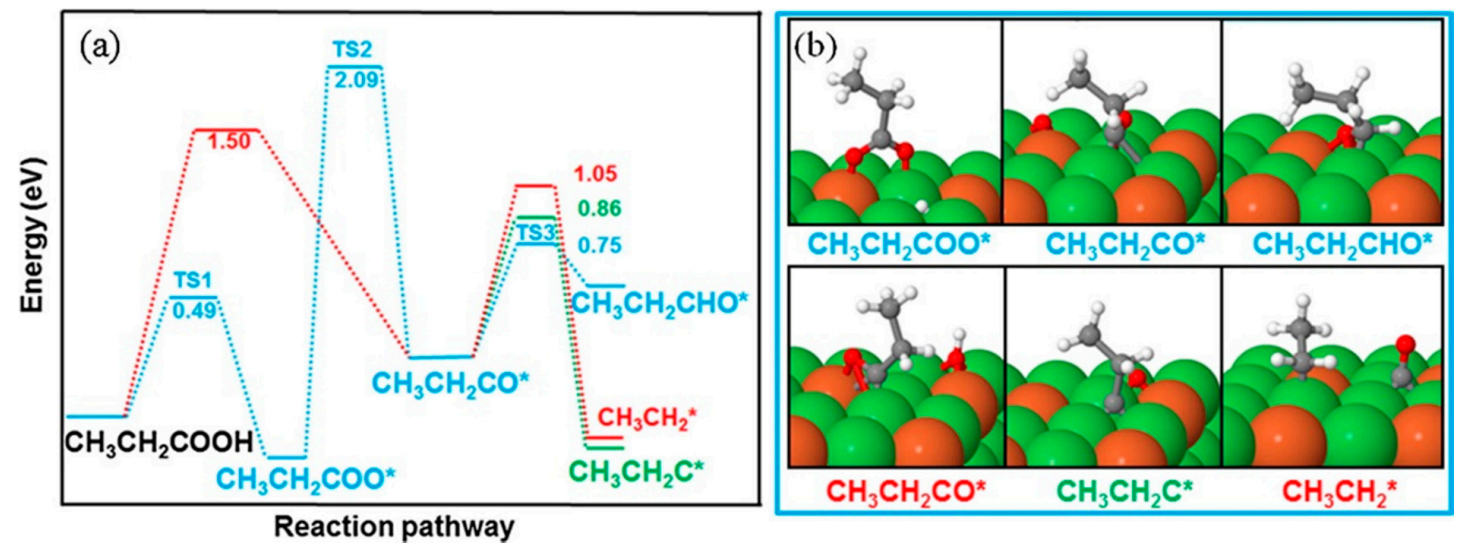

Figure 14. (a) Reaction pathways for the hydrogenation of propanoic acid on a Ni-Fe surface, evidencing the key role of the $\mathrm{CH}_{3}-\mathrm{CH}_{2}-\mathrm{CO}^{*}$ intermediate. (b) DFT-optimized configuration of the investigated intermediates. Reprinted from Reference [27], copyright 2018, with permission from Elsevier.

\subsection{A Surface Excess of Fe on Ni-Fe Nanoparticles?}

Various results from the literature tend to show that the surface of Ni-Fe is poorly ordered, and that Fe atoms may be present in a significant excess in the first atomic layers. The DFT models proposed by Sitthisa et al. for a $\mathrm{Ni}_{50} \mathrm{Fe}_{50}$ (111) surface [21] were based on alternating rows of $\mathrm{Ni}$ and $\mathrm{Fe}$ atoms. The later model developed by the same team included the possibility that Fe atoms could be grouped (Figure 15) [22]. Comparison with Ni, Fe or ordered Ni-Fe surfaces showed that it is in fact the presence of patches of $\mathrm{Fe}$ atoms that would cause a maximum repulsion between an aromatic ring and the metal, explaining the poor activity of $\mathrm{Ni}-\mathrm{Fe}$ system in its hydrogenation.

This hypothesis is in line with several characterization results. According to surface science studies carried out by Vasiliev and Gorodetsky [66], the surface of $\mathrm{Ni}_{75} \mathrm{Fe}_{25}$ single crystals becomes preferentially terminated by Fe atoms upon heating above $350^{\circ} \mathrm{C}$. Several teams have reported that the extended X-ray absorption fine structure (EXAFS) coordination number of $\mathrm{Fe}$ in reduced fcc $\mathrm{Ni}-\mathrm{Fe}$ nanoparticles prepared by co-impregnation is smaller than that of $\mathrm{Ni}[17,18,24,65,67]$. Moreover, when exposed to oxidizing conditions, Fe was shown be more oxidized than $\mathrm{Ni}$, that retained its metallic state and coordination number as if it were preferentially located in the core of the nanoparticles $[18,67]$. Mössbauer data supplied by Shi et al. also pointed to the presence of non-magnetic Fe at the surface of nanoparticles prepared by deposition-precipitation [28]. Ishihara et al. observed that the desorption profile of $\mathrm{H}_{2}$ from a $\mathrm{Ni}_{50} \mathrm{Fe}_{50} / \mathrm{SiO}_{2}$ catalyst was close to that of monometallic $\mathrm{Fe}$, and very different from monometallic Ni [33]. On some of their catalysts, Yu et al. observed by STEM-EDX measurements an enrichment in Fe at the periphery of Ni-Fe nanoparticles [46]. Fang et al. have presented a low-energy ion scattering (LEIS) spectrum confirming a surface enrichment in Fe [32].

A direct link to catalysis was indeed given by Matsuyama et al. in 1986 [20]. By quantifying $\beta$-rays emitted by ${ }^{63} \mathrm{Ni}$, they demonstrated that the surface concentration of $\mathrm{Ni}$ was much lower than what the bulk composition of unsupported alloys would indicate. The maximum activity in the hydrogenation of ethylene was reached for a bulk composition of $50 \% \mathrm{Ni}$, but this corresponded to a surface composition of only $20 \%$ Ni vs. $80 \%$ Fe (Figure 6A). Also in connection with catalysis, Shen and Dumesic have demonstrated that the deposition of Fe atoms onto the surface of Ni nanoparticles by decomposition of $\mathrm{Fe}(\mathrm{CO})_{5}$ progressively lowers the activation energy of the catalyst in the methanation of $\mathrm{CO}$, and increases the reaction order with respect to $\mathrm{H}_{2}$ [68], two characteristics that we have seen before. 


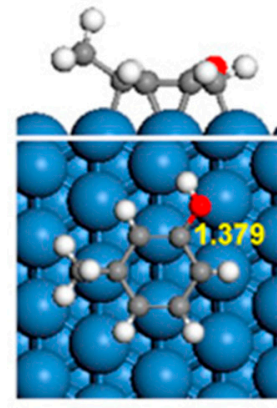

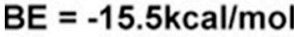

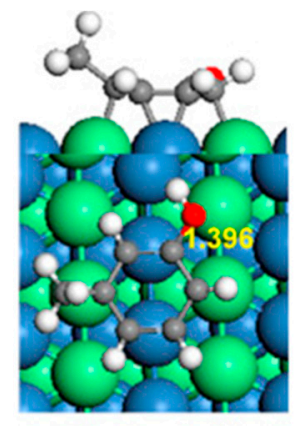

$\mathrm{BE}=-16.5 \mathrm{kcal} / \mathrm{mol}$

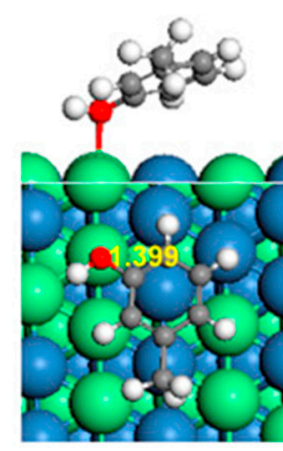

$B E=-4.6 \mathrm{kcal} / \mathrm{mol}$

(a)

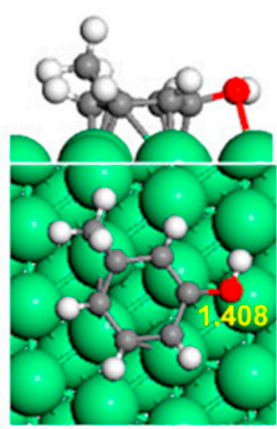

(b)

(c)

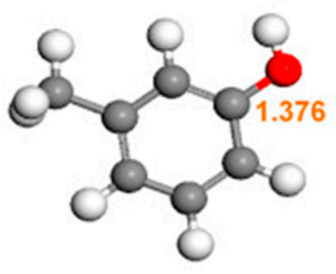

(e)

(d) $\mathrm{BE}=-23.6 \mathrm{kcal} / \mathrm{mol}$

Figure 15. Optimized adsorption structures of meta-cresol on (a) a $\mathrm{Ni}(111)$ surface; (b) a perfect $\mathrm{NiFe}(111)$ surface; (c) a Fe-patched NiFe(111) surface; (d) a Fe(110) surface; (e) gas phase structure. C-O bond lengths are indicated in red and yellow. The comparison between (c) and the other structures evidences the key role of Fe patches in the repulsion of the aromatic ring from the surface. Reprinted from Reference [22], copyright 2014, with permission from Elsevier.

Mizushima et al. [67] and Shi et al. [28] have suggested that this surface enrichment in Fe might be associated to the late reduction of Fe compared to Ni. But it must be remembered that any discussion on the effect of reduction temperature depends on the temperature range one considers. An apparently reverse effect was observed by Bussière et al. in the lower reduction temperatures range [69]. They found by $\mathrm{X}$-ray photoelectron spectroscopy that a $\mathrm{Fe}_{50} \mathrm{Ni}_{50}$ catalyst possessed a Fe/Ni surface ratio of 10 after reduction by hydrogen at $200{ }^{\circ} \mathrm{C}$, and that this ratio decreased to 1.4 after reduction at $400{ }^{\circ} \mathrm{C}$, i.e., when $\mathrm{Ni}$ was completing its reduction. At the same time, the selectivity to methane in $\mathrm{CO}$ hydrogenation increased from $65 \%$ to $90 \%$. In any case, taking the thermal history of the $\mathrm{Ni}-\mathrm{Fe}$ catalyst into account is certainly of importance when one wants to link catalytic properties and surface composition of the nanoparticles.

\section{Conclusions and Perspectives}

Compared to monometallic Ni catalysts, catalysts based on $\mathrm{Ni}-\mathrm{Fe}$ formulations present four characteristics for hydrogenation reactions, both in the gas and in the liquid phase: Higher reaction rates for the hydrogenation of $\mathrm{C}=\mathrm{C}, \mathrm{C}=\mathrm{O}$ and $\mathrm{C} \equiv \mathrm{N}$ bonds; higher selectivity for the hydrogenation of $\mathrm{C} \equiv \mathrm{C}$ bonds or polar functions, with low levels of full hydrogenation, ring-opening or hydrogenolysis side-reactions; in particular, a demonstrated selectivity for the hydrogenation of polar functions, such as that of oxygenates (aldehydes, ketones, furanic compounds, acids, esters, monosaccharides) to alcohols; inhibited hydrogenation of aromatic rings.

Whatever the support, fcc Ni-Fe alloyed phases in the range of formulation $\mathrm{Ni}_{50} \mathrm{Fe}_{50}-\mathrm{Ni}_{80} \mathrm{Fe}_{20}$ tend to provide the best results in terms of activity and selectivity. Formulations close to $\mathrm{Ni}_{75} \mathrm{Fe}_{25} \mathrm{have}$ often been singled out for their activity and selectivity, similarly to what has been found for $\mathrm{CO} / \mathrm{CO}_{2}$ 
hydrogenation or reforming reactions. However, it is currently difficult to firmly conclude that their specificity simply derives from the existence of ordered phases exhibiting this composition, present in the $\mathrm{Ni}-\mathrm{Fe}$ phase diagram, because several questions remain open.

Conclusions purely based on the alloy structure and overall electronic properties are insufficient, as surface effects seems to dominate. Geometric effects may explain, at a simple level, the lower availability of $\mathrm{H}_{2}$ compared to monometallic $\mathrm{Ni}$, and the properties of $\mathrm{Ni}-\mathrm{Fe}$ in selective hydrogenation. A consensus has been currently reached on the dual role of surface $\mathrm{Fe}$ and $\mathrm{Ni}$ atoms, based in their different electronegativity and oxophilicity: Stabilization of specific intermediates onto Ni-Fe pairs for polar molecules, strong back-donation into the antibonding orbitals of the adsorbates resulting in a facilitated hydrogenation. Nevertheless, the investigation of transition states, in order to explain why activation energies are lowered even for simple, non-polar molecules like ethylene or propylene, is still necessary. How Ni-Fe catalysts modify the reactivity of hydrogen is also unclear. Microkinetic modelling will certainly be a useful tool, even if modelling is more difficult for liquid-phase reactions, as solvation effects may be important. Given the evidence for an enrichment of Fe atoms at the surface of $\mathrm{Ni}-\mathrm{Fe}$ systems, models should preferably include patches of $\mathrm{Fe}$ atoms, that may be involved in the repulsion of aromatic rings. Globally speaking, more quantitative measurements are needed to precisely characterize surface compositions.

Before comparing catalytic results, it should also be remembered that on $\mathrm{Ni}-\mathrm{Fe}$ catalysts, the nanoparticles size is not always homogeneous, and sometimes their composition is not homogeneous either. As a synthesis procedure, incipient wetness impregnation is easy to implement, but with some risks in terms of heterogeneities between $\mathrm{Ni}-\mathrm{Fe}$ nanoparticles. Co-precipitation is currently favored for the preparation of supported $\mathrm{Ni}-\mathrm{Fe}$ catalysts displaying homogeneous nanoparticles, but high reduction temperatures may be required to complete the reduction of the two metals. The heterogeneity depends on the preparation method, but also on the support used: Alumina might trap metal ions (mostly Fe), and change the proportion of metals in the nanoparticles compared with the expected formulation. Support roles have been demonstrated for some selective hydrogenations, but they are difficult to rationalize as they can be accompanied by changes in the particle size or composition. The role of unreduced Fe ions in the activation of polar functions is also unclear. The thermal history of the catalyst is probably of importance, as it may play both on the reduction degree of the two metals, and on the Fe surface content. Further progress in the understanding of Ni-Fe catalysts in selective hydrogenation will require the maximum details to be taken into account (homogeneity of particles in size and composition, reduction temperature, degree of reduction of the metals) in order to compare catalytic results obtained at similar levels of conversion or in similar experimental conditions, to identify the right balance in terms of Ni vs. Fe surface composition, and to build realistic DFT and kinetic models.

Author Contributions: D.S. has written the first draft of this review; D.S., R.W., S.P. and E.M. have all contributed to the writing and revision of the manuscript in its final form.

Funding: This work has benefited from the support of the CSC-Ecole Centrale de Lille PhD scholarship program (D.S.), and of the French National Research Agency (ANR), through the NobleFreeCat project (ANR-17-CE07-0022).

Acknowledgments: Chevreul Institute (FR 2638), Ministère de 1'Enseignement Supérieur et de la Recherche, Région Nord-Pas de Calais and FEDER are acknowledged for supporting this work.

Conflicts of Interest: The authors declare no conflict of interest. The funders had no role in the design of the study, in the collection, analyses, or interpretation of data; in the writing of the manuscript, or in the decision to publish the results.

\section{References}

1. Wainwright, M.S. Skeletal catalysts. In Preparation of Solid Catalysts, 1st ed.; Ertl, G., Knözinger, H., Weitkamp, J., Eds.; Wiley-VCH: Weinheim, Germany, 1999; pp. 28-43.

2. De, S.; Zhang, J.; Luque, R.; Yan, N. Ni-based bimetallic heterogeneous catalysts for energy and environmental applications. Energy Environ. Sci. 2016, 9, 3314-3347. [CrossRef] 
3. Koike, M.; Li, D.; Nakagawa, Y.; Tomishige, K. A highly active and coke-resistant steam reforming catalyst comprising uniform nickel-iron alloy nanoparticles. ChemSusChem 2012, 5, 2312-2314. [CrossRef]

4. Li, D.; Koike, M.; Wang, L.; Nakagawa, Y.; Xu, Y.; Tomishige, K. Regenerability of hydrotalcite-derived nickel-iron alloy nanoparticles for syngas production from biomass tar. ChemSusChem 2014, 7, 510-522. [CrossRef] [PubMed]

5. Tomishige, K.; Li, D.; Tamura, M.; Nakagawa, Y. Nickel-iron alloy catalysts for reforming of hydrocarbons: Preparation, structure, and catalytic properties. Catal. Sci. Technol. 2017, 7, 3952-3979. [CrossRef]

6. Laosiripojana, N.; Sutthisripok, W.; Charojrochkul, S.; Assabumrungrat, S. Conversion of biomass tar containing sulphur to syngas by $\mathrm{GdCeO}_{2}$ coated NiFe bimetallic-based catalysts. Appl. Catal. A 2014, 478, 9-14. [CrossRef]

7. Bhavani, A.G.; Kim, W.Y.; Lee, J.W.; Lee, J.S. Influence of metal particle size on oxidative $\mathrm{CO}_{2}$ reforming of methane over supported nickel catalysts: Effects of second-metal addition. ChemCatChem 2015, 7, 1445-1452. [CrossRef]

8. Kim, S.M.; Macarena Abdala, P.; Margossian, T.; Hosseini, D.; Foppa, L.; Armutlulu, A.; Van Beek, W.; Comas-Vives, A.; Copéret, C.; Müller, C. Cooperativity and dynamics increase the performance of NiFe dry reforming catalysts. J. Am. Chem. Soc. 2017, 139, 1937-1949. [CrossRef]

9. Andersson, M.; Bligaard, T.; Kustov, A.; Larsen, K.; Greeley, J.; Johannessen, T.; Christensen, C.; Nørskov, J. Toward computational screening in heterogeneous catalysis: Pareto-optimal methanation catalysts. J. Catal. 2006, 239, 501-506. [CrossRef]

10. Kustov, A.L.; Frey, A.M.; Larsen, K.E.; Johannessen, T.; Nørskov, J.K.; Christensen, C.H. CO methanation over supported bimetallic Ni-Fe catalysts: From computational studies towards catalyst optimization. Appl. Catal. A 2007, 320, 98-104. [CrossRef]

11. Sehested, J.; Larsen, K.E.; Kustov, A.L.; Frey, A.M.; Johannessen, T.; Bligaard, T.; Andersson, M.P.; Nørskov, J.K.; Christensen, C.H. Discovery of technical methanation catalysts based on computational screening. Top. Catal. 2007, 45, 9-13. [CrossRef]

12. Hwang, S.; Hong, U.G.; Lee, J.; Baik, J.H.; Koh, D.J.; Lim, H.; Song, I.K. Methanation of carbon dioxide over mesoporous nickel-M-Alumina ( $\mathrm{M}=\mathrm{Fe}, \mathrm{Zr}, \mathrm{Ni}, \mathrm{Y}$, and $\mathrm{Mg}$ ) xerogel catalysts: Effect of second metal. Catal. Lett. 2012, 142, 860-868. [CrossRef]

13. Hwang, S.; Lee, J.; Hong, U.G.; Jung, J.C.; Koh, D.J.; Lim, H.; Byun, C.; Song, I.K. Hydrogenation of carbon monoxide to methane over mesoporous nickel-M-alumina ( $\mathrm{M}=\mathrm{Fe}, \mathrm{Ni}, \mathrm{Co}, \mathrm{Ce}$, and $\mathrm{La})$ xerogel catalysts. J. Ind. Eng. Chem. 2012, 18, 243-248. [CrossRef]

14. Pandey, D.; Deo, G. Promotional effects in alumina and silica supported bimetallic Ni-Fe catalysts during $\mathrm{CO}_{2}$ hydrogenation. J. Mol. Catal. A 2014, 382, 23-30. [CrossRef]

15. Pandey, D.; Ray, K.; Bhardwaj, R.; Bojja, S.; Chary, K.V.R.; Deo, G. Promotion of unsupported nickel catalyst using iron for $\mathrm{CO}_{2}$ methanation. Int. J. Hydrogen Energy 2018, 43, 4987-5000. [CrossRef]

16. Mebrahtu, C.; Krebs, F.; Perathoner, S.; Abate, S.; Centi, G.; Palkovits, R. Hydrotalcite based Ni-Fe/(Mg,Al)O catalysts for $\mathrm{CO}_{2}$ methanation-Tailoring Fe content for improved $\mathrm{CO}$ dissociation, basicity, and particle size. Catal. Sci. Technol. 2018, 8, 1016-1027. [CrossRef]

17. Kumbhar, P.S.; Kharkar, M.R.; Yadav, G.D.; Rajadhyaksha, R.A. Geometric and electronic effects in silica supported bimetallic nickel copper and nickel iron catalysts for liquid-phase hydrogenation of acetophenone and benzonitrile. J. Chem. Soc. Chem. Commun. 1992, 7, 584-586. [CrossRef]

18. Wang, L.; Li, D.; Koike, M.; Koso, S.; Nakagawa, Y.; Xu, Y.; Tomishige, K. Catalytic performance and characterization of $\mathrm{Ni}$-Fe catalysts for the steam reforming of tar from biomass pyrolysis to synthesis gas. Appl. Catal. A 2011, 392, 248-255. [CrossRef]

19. Bradley, A.J.; Jay, A.H.; Taylor, A.M. LIII. The lattice spacing of iron-nickel alloys. Lond. Edinb. Dublin Philos. Mag. J. Sci. 1937, 23, 545-557. [CrossRef]

20. Matsuyama, M.; Ashida, K.; Takayasu, O.; Takeuchi, T. Catalytic activities of Ni alloys expressed by surface and bulk compositions. J. Catal. 1986, 102, 309-315. [CrossRef]

21. Sitthisa, S.; An, W.; Resasco, D.E. Selective conversion of furfural to methylfuran over silica-supported NiFe bimetallic catalysts. J. Catal. 2011, 284, 90-101. [CrossRef]

22. Nie, L.; De Souza, P.M.; Noronha, F.B.; An, W.; Sooknoi, T.; Resasco, D.E. Selective conversion of m-cresol to toluene over bimetallic Ni-Fe catalysts. J. Mol. Catal. A 2014, 388-389, 47-55. [CrossRef] 
23. Unmuth, E.E.; Schwartz, L.H.; Butt, J.B. Iron alloy Fischer-Tropsch catalysts. I. Oxidation-reduction studies of the Fe-Ni system. J. Catal. 1980, 61, 242-255. [CrossRef]

24. Rao, C.N.R.; Kulkarni, G.U.; Kannan, K.R.; Chaturvedi, S. In situ Mössbauer and EXAFS investigations of the structural and magnetic-properties of bimetallic $\mathrm{Fe}-\mathrm{Ni} / \mathrm{SiO}_{2}$ and $\mathrm{Fe}-\mathrm{Cu} / \mathrm{SiO}_{2}$ catalysts. J. Phys. Chem. 1992, 96, 7379-7385. [CrossRef]

25. Raupp, G.B.; Delgass, W.N. Mössbauer investigation of supported Fe and FeNi catalysts. I. Effect of pretreatment on particle-size. J. Catal. 1979, 58, 337-347. [CrossRef]

26. Putro, W.S.; Kojima, T.; Hara, T.; Ichikuni, N.; Shimazu, S. Selective hydrogenation of unsaturated carbonyls by Ni-Fe-based alloy catalysts. Catal. Sci. Technol. 2017, 7, 3637-3646. [CrossRef]

27. Kong, X.; Fang, Z.; Bao, X.; Wang, Z.; Mao, S.; Wang, Y. Efficient hydrogenation of stearic acid over carbon coated Ni-Fe catalyst. J. Catal. 2018, 367, 139-149. [CrossRef]

28. Shi, D.; Yang, Q.; Peterson, C.; Lamic-Humblot, A.F.; Girardon, J.S.; Griboval-Constant, A.; Stievano, L.; Sougrati, M.T.; Briois, V.; Bagot, P.A.J.; et al. Bimetallic Fe-Ni/SiO 2 catalysts for furfural hydrogenation: Identification of the interplay between $\mathrm{Fe}$ and $\mathrm{Ni}$ during deposition-precipitation and thermal treatments. Catal. Today 2018. [CrossRef]

29. Lü, X.; Zhang, Q.; Yang, W.; Li, X.; Zeng, L.; Li, L. Catalytic ozonation of 2,4-dichlorophenoxyacetic acid over novel Fe-Ni/AC. RSC Adv. 2015, 5, 10537-10545. [CrossRef]

30. Guerrero-Ruiz, A.; Sepúlveda-Escribano, A.; Rodríguez-Ramos, I. Carbon-supported bimetallic catalysts containing iron. I. Preparation and characterization. Appl. Catal. A 1992, 81, 81-100. [CrossRef]

31. Guerrero-Ruiz, A.; Sepúlveda-Escribano, A.; Rodríguez-Ramos, I. Carbon-supported bimetallic catalysts containing iron. II. Catalytic behaviour in benzene hydrogenation and thiophene hydrodesulphurization. Appl. Catal. A 1992, 81, 101-112. [CrossRef]

32. Fang, H.; Zheng, J.; Luo, X.; Du, J.; Roldan, A.; Leoni, S.; Yuan, Y. Product tunable behavior of carbon nanotubes-supported Ni-Fe catalysts for guaiacol hydrodeoxygenation. Appl. Catal. A 2017, 529, $20-31$. [CrossRef]

33. Ishihara, T.; Eguchi, K.; Arai, H. Hydrogenation of carbon-monoxide over $\mathrm{SiO}_{2}$-supported Fe-Co, Co-Ni and Ni-Fe bimetallic catalysts. Appl. Catal. 1987, 30, 225-238. [CrossRef]

34. Chieffi, G.; Giordano, C.; Antonietti, M.; Esposito, D. FeNi nanoparticles with carbon armor as sustainable hydrogenation catalysts: Towards biorefineries. J. Mater. Chem. A 2014, 2, 11591-11596. [CrossRef]

35. Feyzi, M.; Mirzaei, A.A. Preparation and characterization of $\mathrm{FeNi} / \mathrm{Al}_{2} \mathrm{O}_{3}$ catalysts for production of light olefins. Petrol. Chem. 2012, 52, 362-371. [CrossRef]

36. Liu, Q.; Qiao, Y.; Tian, Y.; Gu, F.; Zhong, Z.; Su, F. Ordered mesoporous Ni-Fe-Al catalysts for CO methanation with enhanced activity and resistance to deactivation. Ind. Eng. Chem. Res. 2017, 56, 9809-9820. [CrossRef]

37. Ashok, J.; Kawi, S. Nickel-iron alloy supported over iron-alumina catalysts for steam reforming of biomass tar model compound. ACS Catal. 2014, 4, 289-301. [CrossRef]

38. Li, T.; Wang, H.; Yang, Y.; Xiang, H.; Li, Y. Study on an iron-nickel bimetallic Fischer-Tropsch synthesis catalyst. Fuel Process. Technol. 2014, 118, 117-124. [CrossRef]

39. Zhai, Y.; Li, C.; Xu, G.; Ma, Y.; Liu, X.; Zhang, Y. Depolymerization of lignin via a non-precious Ni-Fe alloy catalyst supported on activated carbon. Green Chem. 2017, 19, 1895-1903. [CrossRef]

40. Zhang, Y.; Liu, C.; Fan, G.; Yang, L.; Li, F. A robust core-shell nanostructured nickel-iron alloy@nitrogen-containing carbon catalyst for the highly efficient hydrogenation of nitroarenes. Dalton Trans. 2018, 47, 13668-13679. [CrossRef]

41. Mutz, B.; Belimov, M.; Wang, W.; Sprenger, P.; Serrer, M.A.; Wang, D.; Pfeifer, P.; Kleist, W.; Grunwaldt, J.D. Potential of an alumina-supported $\mathrm{Ni}_{3} \mathrm{Fe}$ catalyst in the methanation of $\mathrm{CO}_{2}$ : Impact of alloy formation on activity and stability. ACS Catal. 2017, 7, 6802-6814. [CrossRef]

42. Li, C.; Xu, G.; Zhai, Y.; Liu, X.; Ma, Y.; Zhang, Y. Hydrogenation of biomass-derived ethyl levulinate into $\gamma$-valerolactone by activated carbon supported bimetallic Ni and Fe catalysts. Fuel 2017, 203, $23-31$. [CrossRef]

43. Van de Loosdrecht, J.; van Dillen, A.J.; Vanderhorst, A.A.; van der Kraan, A.M.; Geus, J.W. Nickel-iron catalysts prepared by homogeneous deposition-precipitation of cyanide complexes on a titania support. Top. Catal. 1995, 2, 29-43. [CrossRef]

44. Van de Loosdrecht, J.; van der Kraan, A.M.; van Dillen, A.J.; Geus, J.W. Metal-support interaction: Titania-supported nickel-iron catalysts. Catal. Lett. 1996, 41, 27-34. [CrossRef] 
45. Brown, R.; Cooper, M.E.; Whan, D.A. Temperature programmed reduction of alumina-supported iron, cobalt and nickel bimetallic catalysts. Appl. Catal. 1982, 3, 177-186. [CrossRef]

46. Yu, X.; Chen, J.; Ren, T. Promotional effect of Fe on performance of $\mathrm{Ni} / \mathrm{SiO}_{2}$ for deoxygenation of methyl laurate as a model compound to hydrocarbons. RSC Adv. 2014, 4, 46427-46436. [CrossRef]

47. Oemar, U.; Ang, P.S.; Hidajat, K.; Kawi, S. Promotional effect of Fe on perovskite $\mathrm{LaNi}_{\mathrm{x}} \mathrm{Fe}_{1-\mathrm{x}} \mathrm{O}_{3}$ catalyst for hydrogen production via steam reforming of toluene. Int. J. Hydrogen Energy 2013, 38, 5525-5534. [CrossRef]

48. Jiang, X.Z.; Stevenson, S.A.; Dumesic, J.A.; Kelly, T.F.; Casper, R.J. Characterization of NiFe alloy particles supported on titania and alumina-scanning-transmission electron-microscopy, magnetic-susceptibility, Mössbauer-spectroscopy and chemisorption measurements. J. Phys. Chem. 1984, 88, 6191-6198. [CrossRef]

49. Kojima, T.; Fujieda, S.; Kato, G.; Kameoka, S.; Suzuki, S.; Tsai, A.P. Hydrogenation of propyne verifying the harmony in surface and bulk compositions for Fe-Ni alloy nanoparticles. Mater. Trans. JIM 2017, 58, 776-781. [CrossRef]

50. Gallezot, P.; Cerino, P.J.; Blanc, B.; Flèche, G.; Fuertes, P. Glucose hydrogenation on promoted Raney-nickel catalysts. J. Catal. 1994, 146, 93-102. [CrossRef]

51. Yadav, G.D.; Kharkara, M.R. Liquid-phase hydrogenation of saturated and unsaturated nitriles - activities and selectivties of bimetallic nickel-copper and nickel-iron catalysts supported on silica. Appl. Catal. A 1995, 126, 115-123. [CrossRef]

52. Gao, S.; Tang, Y.; Wang, L.; Liu, L.; Jia, D.; Zhao, Z. NiFe nanoalloys in-situ immobilized on coal based activated carbons through one-step pyrolysis as magnetically recoverable catalysts for reduction of 4-nitrophenol. J. Alloys Compd. 2017, 702, 531-537. [CrossRef]

53. Leng, S.; Wang, X.; He, X.; Liu, L.; Liu, Y.; Zhong, X.; Zhuang, G.; Wang, J.G. NiFe $/ \gamma-\mathrm{Al}_{2} \mathrm{O}_{3}$ : A universal catalyst for the hydrodeoxygenation of bio-oil and its model compounds. Catal. Commun. 2013, 41, 34-37. [CrossRef]

54. Liu, X.; An, W.; Turner, C.H.; Resasco, D.E. Hydrodeoxygenation of m-cresol over bimetallic NiFe alloys: Kinetics and thermodynamics insight into reaction mechanism. J. Catal. 2018, 359, 272-286. [CrossRef]

55. Chen, S.; Wojcieszak, R.; Dumeignil, F.; Marceau, E.; Royer, S. How catalysts and experimental conditions determine the selective hydroconversion of furfural and 5-hydroxymethylfurfural. Chem. Rev. 2018, 22, 11023-11117. [CrossRef]

56. Wang, C.; Luo, J.; Lee, J.D.; Onn, T.M.; Murray, C.B.; Gorte, R.J. A comparison of furfural hydrodeoxygenation over Pt-Co and Ni-Fe catalysts at high and low $\mathrm{H}_{2}$ pressure. Catal. Today 2018, 302, 73-79. [CrossRef]

57. Halilu, A.; Ali, T.H.; Atta, A.Y.; Sudarsanam, P.; Bhargava, S.K.; Abd Hamid, S.B. Highly selective hydrogenation of biomass-derived furfural into furfuryl alcohol using a novel magnetic nanoparticles catalyst. Energy Fuels 2016, 30, 2216-2226. [CrossRef]

58. Yu, L.; He, L.; Chen, J.; Zheng, J.; Ye, L.; Lin, H.; Yuan, Y. Robust and recyclable nonprecious bimetallic nanoparticles on carbon nanotubes for the hydrogenation and hydrogenolysis of 5-hydroxymethylfurfural. ChemCatChem 2015, 7, 1701-1707. [CrossRef]

59. Arai, H.; Mitsuishi, K.; Seiyama, T. TiO 2 -supported Fe-Co, Co-Ni and Ni-Fe alloy catalysts for Fischer-Tropsch synthesis. Chem. Lett. 1984, 8, 1291-1294. [CrossRef]

60. Tian, D.; Liu, Z.; Li, D.; Shi, H.; Pan, W.; Cheng, Y. Bimetallic Ni-Fe total-methanation catalyst for the production of substitute natural gas under high pressure. Fuel 2013, 104, 224-229. [CrossRef]

61. Ray, K.; Deo, G. A potential descriptor for the $\mathrm{CO}_{2}$ hydrogenation to $\mathrm{CH}_{4}$ over $\mathrm{Al}_{2} \mathrm{O}_{3}$ supported $\mathrm{Ni}$ and Ni-based alloy catalysts. Appl. Catal. B 2017, 218, 525-537. [CrossRef]

62. Ray, K.; Bhardwaj, R.; Singh, B.; Deo, G. Developing descriptors for $\mathrm{CO}_{2}$ methanation and $\mathrm{CO}_{2}$ reforming of $\mathrm{CH}_{4}$ over $\mathrm{Al}_{2} \mathrm{O}_{3}$ supported $\mathrm{Ni}$ and low-cost $\mathrm{Ni}$ based alloy catalysts. Phys. Chem. Chem. Phys. 2018, 20, 15939-15950. [CrossRef]

63. Yu, W.; Chen, J.G. Reaction pathways of model compounds of biomass-derived oxygenates on Fe/Ni bimetallic surfaces. Surf. Sci. 2015, 640, 159-164. [CrossRef]

64. Ishihara, T.; Eguchi, K.; Arai, H. An infrared study of $\mathrm{NO}$ adsorbed on $\mathrm{SiO}_{2}$-supported Fe, $\mathrm{Co}$ and $\mathrm{Ni}$ bimetallic alloy catalysts for CO hydrogenation. Chem. Lett. 1986, 10, 1695-1698. [CrossRef]

65. Yu, W.; Xiong, K.; Ji, N.; Porosoff, M.D.; Chen, J.G. Theoretical and experimental studies of the adsorption geometry and reaction pathways of furfural over FeNi bimetallic model surfaces and supported catalysts. J. Catal. 2014, 317, 253-262. [CrossRef] 
66. Vasiliev, M.A.; Gorodetsky, S.D. Composition and dynamical characteristics of the surface of single crystals $\mathrm{FeNi}_{3}$ (100), (110), (111). Surf. Sci. 1986, 171, 543-554. [CrossRef]

67. Mizushima, T.; Tohji, K.; Udagawa, Y.; Harada, M.; Ishikawa, M.; Ueno, A. Characterization of silica-supported bimetallic iron-nickel catalysts by EXAFS. J. Catal. 1988, 112, 282-289. [CrossRef]

68. Shen, W.M.; Dumesic, J.A. Deactivation of nickel methanation catalysts induced by the decomposition of iron carbonyl. II. Interactions between iron and nickel. J. Catal. 1983, 84, 135-144. [CrossRef]

69. Bussiere, P.; Duvault, J.L.; Forissier, M.; Foujols, D.; Mirodatos, C.; Perrichon, V. Relationship between the catalytic properties and surface-composition of a polycrystalline Fe-Ni ribbon. Appl. Catal. 1990, 58, 219-225. [CrossRef]

(C) 2019 by the authors. Licensee MDPI, Basel, Switzerland. This article is an open access article distributed under the terms and conditions of the Creative Commons Attribution (CC BY) license (http://creativecommons.org/licenses/by/4.0/). 